\title{
Meta- analysis and meta-regression analysis of the associations between sex and the operative outcomes of carotid endarterectomy
}

Thomas Luebke* and Jan Brunkwall

\begin{abstract}
Background: Subgroup analyses from randomized controlled trials (RCT) of carotid endarterectomy (CEA) for both symptomatic and asymptomatic carotid stenosis suggest less benefit in women compared to men, due partly to higher age-independent peri-operative risk. However, a meta-analysis of case series and databases focussing on CEA-related gender differences has never been investigated.

Methods: A systematic review of all available publications (including case series, databases and RCTs) reporting data on the association between sex and procedural risk of stroke and/or death following CEA from 1980 to 2015 was investigated. Pooled Peto odds ratios of the procedural risk of stroke and/or death were obtained by Mantel-Haenszel random-effects meta-analysis. The $\mathrm{I}^{2}$ statistic was used as a measure of heterogeneity. Potential publication bias was assessed with the Egger test and represented graphically with Begg funnel plots of the natural log of the OR versus its standard error. Additional sensitivity analyses were undertaken to evaluate the potential effect of key assumptions and study-level factors on the overall results. Meta-regression models were formed to explore potential heterogeneity as a result of potential risk factors or confounders on outcomes. A tria sequential analysis (TSA) was performed with the aim to maintain an over- all $5 \%$ risk of type I error, being the standard in most meta- analyses and systematic reviews.

Results: 58 articles reported combined stroke and mortality rates within 30 days of treatment. In the unselected overall meta-analysis, the incidence of stroke and death in the male and female groups differed significantly (Peto $\mathrm{OR}, 1,162 ; 95 \% \mathrm{Cl}, 1.067-1.266 ; P=.001)$, revealing a worse outcome for female patients. Moderate heterogeneity among the studies was identified $\left(P^{2}=36 \%\right)$, and the possibility of publication bias was low $(P=.03)$. In sensitivity analyses the meta-analysis of case series with gender aspects as a secondary outcome showed a significantly increased risk for 30-day stroke and death in women compared to men (Peto OR, 1.390; 95 \% Cl, 1.148-1.684; $P=.001$ ), In contrast, meta-analysis of databases (Peto OR, 1.025; $95 \% \mathrm{Cl}, 0.958-1.097 ; P=.474$ ) and case series with gender related outcomes as a primary aim (Peto OR, 1.202; $95 \% \mathrm{Cl}, 0.925-1.561 ; P=.168$ ) demonstrated no increase in operative risk of stroke and death in women compared to men.
\end{abstract}

Conclusions: Metanalyses of case series and databases dealing with CEA reveal inconsistent results regarding gender differences related to CEA-procedure and should not be transferred into clinical practice.

Keywords: Carotid endarterectomy, Complications, Meta-analysis, Meta-regression, Sex, Gender

\footnotetext{
* Correspondence: Thomas.luebke@uk-koeln.de

Department of Vascular and Endovascular Surgery, University Hospital of

Cologne, Kerpener Str. 62, 50937 Cologne, Germay
} 


\section{Background}

Carotid endarterectomy (CEA) has been shown to be a more effective therapeutic option compared to the best medical treatment alone in the prevention of ischemic stroke, with acceptably low perioperative (30-day) stroke and death rates [1-4]. The subgroup analyses of NASCET (North American Symptomatic Carotid Endarterectomy Trial), ACAS (Asymptomatic Carotid Atherosclerosis Study), and ECST (European Carotid Surgery Trial) suggested that CEA may not be as efficacious in women as it is in men $[5,6]$ and that women might have higher risk of perioperative adverse events compared to men [1, 2]. It has been speculated, that the lower magnitude of benefit in women was due partly to a slightly higher operative risk in women as compared to men combined with the lower natural history risk of stroke in women [5-7]. However, it is not clear whether these subgroup analyses can be transferred to a non-trial setting because the CEA trials had specific inclusion and exclusion criteria. Moreover, even among patients who are eligible for randomisation, it is known from other trials that there are systematic differences between patients who are recruited and those who are not [8] and trial recruitment tends to be most selective in women [9]. Whereas a considerable body of literature challenges the overall benefit of CEA in unselected women compared to men, other studies on larger CEA databases suggested no substantial gender differences [10, 11]. Therefore it is crucial to determine whether the gender related differences of operative risks in women in the trials of CEA are also present in routine clinical practice. Since only operative mortality, rather than the risk of stroke and death, is recorded in the large-scale statewide or national reports of routinely collected data on outcome after CEA [12-15], a meta-analysis of all available publications (including case series, databases and RCTs) published during 1980-2015 that reported the perioperative risk of stroke and death following CEA by gender was performed.

\section{Methods}

\section{Information sources and search strategy}

We conducted PubMed (1950 to present), EMBASE (1980 to present), and Cochrane Central Register of Controlled Trials searches using the Medical Subject Headings terms endarterectomy, carotid, stents, and carotid stenosis and combining them with key terms associated with sex (eg, sex, gender, men, male, women, and female) and the word risk. The last search was run in January 2015. A secondary search consisted of manual scrutiny of the reference lists of review articles, meta-analyses, and original studies identified by the electronic searches to find other eligible trials. There was no language restriction for the search.

\section{Eligibility criteria}

All published studies reporting 30-day (or similar) perioperative risk of stroke and/or death following CEA for symptomatic or asymptomatic stenosis, which stratified their results according to patient sex either as the main objective of the study or as a substudy were considered.

Studies were included if they fulfilled the following criteria:

1) The numbers of combined strokes and/or deaths occurring within 30 days of CEA (or similar time period) were reported.

2) The risks of stroke and/or death were defined, or calculable, per operation.

3) Operative risks were reported according to sex of the patients.

Studies were excluded if:

1) They concerned carotid surgery for non-atherosclerotic disease.

2) They included patients undergoing bilateral simultaneous CEA and did not report data separately on patients undergoing unilateral procedures.

3) They included patients undergoing synchronous CEA and coronary artery bypass grafting and did not report data separately on patients undergoing CEA only.

4) They concerned the risks of surgery in a specific sex but did not report data on the other sex.

\section{Data collection}

The data sought included (1) study characteristics (year of publication, patient recruitment period, number of patients or procedures); (2) baseline demographic and clinical characteristics of the patients (age, sex, hypertension, diabetes mellitus, coronary artery disease, peripheral artery disease, dyslipidemia, smoking status, and symptomatic or asymptomatic carotid disease); (3) procedural characteristics (type of anesthesia, use of shunt, and type of CEA [primary or redo $\mathrm{CEA}]$ ); and (4) outcome parameters, as defined above.

\section{Quality assessment}

Study quality was quantified with the Newcastle-Ottawa Scale [16] for case-control observational studies. The Jadad scale was applied for the assessment of RCTs [17].

\section{Statistical analysis \\ Overall analyses}

Meta-analyses were performed to calculate the overall relative odds of death, and combined stroke and death according to sex by the Mantel-Haenszel method. The 
Peto method for odds ratios (ORs) $[18,19]$ was used for studies with few events. To counterbalance random effects of the different studies, such as variabilities of baseline characteristics, the summary estimates of Peto ORs was applied. Intention-to-treat meta-analysis was performed in line with recommendations from the Cochrane Collaboration and the Preferred Reporting Items for Systematic Reviews and Meta- analyses Statement [20] using standard software (Comprehensive Meta-Analysis 2.0 software, Biostat, Englewood, NJ).

\section{Sensitivity analyses}

Analyses were also performed separately for trial (RCTs) and non-trial populations (databases and case-series) and, among non-trial populations, for studies in which the effect of sex on operative risk was the primary focus (primary aim) of the study versus those where it was reported as a subanalysis, usually along with other risk factors (secondary aim). Where the data were reported, the proportions of asymptomatic patients patients amongst females versus males were determined also. In order to analyse those studies separately with a contemporary and adequate best medical treatment and surgical procedure a cut-off was set for the last ten years, analysing studies published before the year 2004 versus those published after the year 2004. The difference between the estimates of the subgroups was analysed according to tests for interaction [21]. $P<.05$ indicates that the effects of treatment differ between the tested subgroups.

\section{Proof of heterogeneity and bias}

Heterogeneity was assessed using the $\mathrm{I}^{2}$ statistic [22]. $\mathrm{I}^{2}$ is the proportion of total variation observed between the trials attributable to differences between trials rather than sampling error (chance), with $I^{2}<25 \%$ considered low and $I^{2}>75 \%$ considered high. Potential publication bias (ie, bias resulting from the greater likelihood of publishing favourable results) was assessed with the Egger test and represented graphically with Begg funnel plots of the natural $\log$ of the OR versus its standard error [23, 24].

\section{Meta-regression}

A full meta-analysis random-effect approach to the regression had been used, where studies are weighted by a combination of their within-study variance and the degree of heterogeneity. In detail, meta-regression models were formed to explore potential heterogeneity as a result of changes in practice over time and to evaluate the effect of age and other risk factors or potential confounders on outcomes (coronary artery disease, peripheral artery disease, arterial hypertension, diabetes mellitus, dyslipidemia, smoking status, symptom status). We used residual maximum likelihood to estimate the additive (between-study) component of variance 2 for the metaregression analysis.
Bootstrap analyses were performed using a Monte Carlo permutation test for metaregression using 10000 random permutations [25].

\section{Trial sequential analysis}

Cumulative meta-analysis of trials is at risk for producing random errors because of few data and repetitive testing of accumulating data, and the information size requirement analogous to the sample size of a single optimally powered clinical trial may not be met $[26,27]$. In order to quantify the risk for random errors a trial sequential analysis (TSA) was performed The underlying assumption for TSA is that significance testing is performed each time a new trial is published. The TSA depends on the quantification of the required information size. In this context, the smaller the required information size is, the more lenient the TSA is, thus the more lenient the criteria are for statistical significance $[26,27]$. The TSA was performed with a desire to maintain an over- all $5 \%$ risk of type I error, being the standard in most meta- analyses and systematic reviews, and we calculated the required information size (ie, the meta-analysis information size needed to detect or reject an intervention effect of a $20 \%$ [or $15 \%$ ] relative risk increase $[R R I]$ with a $20 \%$ risk of type II error and power of $80 \%)[26,27]$.

\section{Results}

Our literature search yielded a total of 3806 unique articles on CEA of which 58 were eligible for this review (Fig. 1 shows the flow diagram of study selection for the analysis), totalling 8 RCTs, 12 databases and 38 caseseries [1-3, 10, 11, 28-85]. 4 records had been excluded because they were series from the same institutions with duplicate clinical material. A further 6 articles had been excluded because they were reviews, or populationbased studies from which accurate data could not be extracted. Another 3738 records were excluded because the title or the abstract were not relevant. This left 58 studies for analysis reporting data on sex and perioperative risk of CEA. The total number of CEAs included in our analysis was 468 045, of which 188168 (40.2\%) were undertaken in women and the remaining 279877 (59.8 \%) CEAs were performed in male patients. Studies reporting CEAs were published between 1988 and 2014, whereas the patient recruitment period expanded from 1971 through 2013. The methodologic quality of the RCTs, represented in the Jadad score, was low. Similarly, a small proportion of the observational studies achieved a NOS score $>6$ (15 of 58 studies). Main demographic and clinical features of the study populations are outlined in Table 1. 


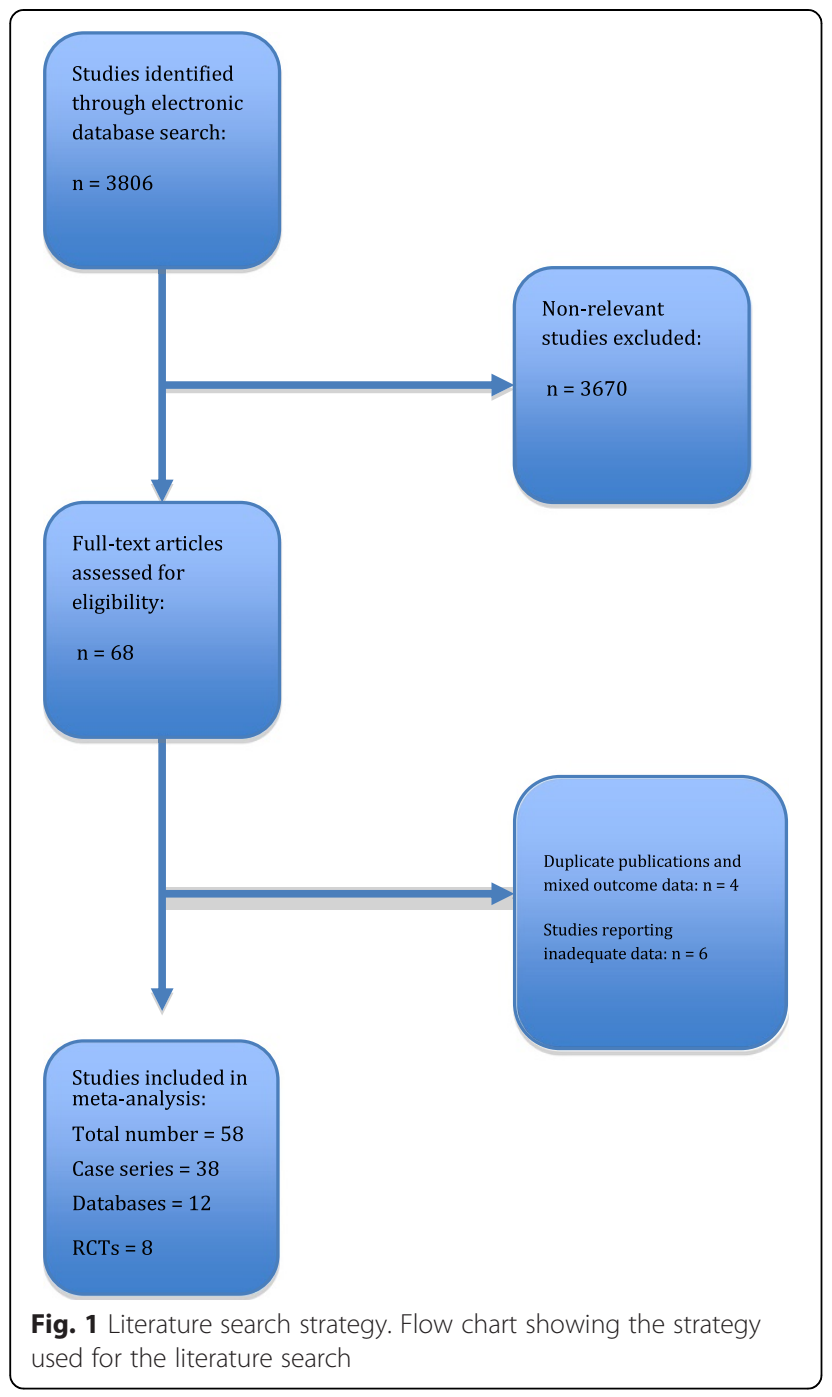

\section{Overall analyses}

\section{Combined 30-day stroke and mortality rate}

All 58 articles reported combined stroke and mortality rates perioperatively or within 30 days of treatment (Fig. 2). The incidence of stroke and death in the male and female groups was 4.609/279 877 (1.6\%) and 3 254/ 188168 (1.7\%), respectively, and this difference was statistically significant (Peto OR, 1,162; 95 \% CI, 1.0671.266; $P=.001$ ). Moderate heterogeneity among the studies was identified $\left(I^{2}=36 \%\right)$, and the possibility of publication bias was low $(P=.03)$.

\section{0-day stroke rate}

40 studies reported 30-day stroke rates in both gender groups $[3,4,10,11,29-32,34-42,52-54,58-60,62-67$, 72-74, 76-80, 84-86] (Fig. 3). The overall stroke rate within 30 days of treatment for men and women were 2 916/242 494 (1.2\%) and 2 110/163 346 (1.3\%), respectively, and the difference between the groups was significant
(Peto OR, 1.204; 95 \% CI, 1.073-1.351; $P=.002$ ). Moderate heterogeneity among the studies existed $\left(I^{2}=47.9 \%\right)$, and the likelihood of publication bias was low $(P=.04)$.

\section{Sensitivity analyses}

\section{Combined 30-day stroke and mortality rate}

Case series - primary aim Among the 21 studies [29-34, $36-38,40,59,62,66,67,69,72,76,78,79,84,85]$ reporting combined 30-day stroke and mortality rates as their primary aim there was no difference in the association between sex and the combined end-point when applying the random-effects model (Peto OR, 1.202; $95 \% \mathrm{CI}$, $0.925-1.561 ; P=.168)$.

However, when applying the fixed-effects model for the same subset of data, there was a statistically significant difference between the two genders regarding the combined end-point 30-day mortality and stroke rate (Peto OR, 1.299; $95 \%$ CI, 1.089-1.548; $P=.004)$. Moderate heterogeneity among the studies existed $\left(I^{2}=32.9 \%\right)$, and the likelihood of publication bias was low $(P=.23)$.

\section{Case series - secondary aim}

Among the 17 [41-52, 54-56, 77, 81] studies reporting combined 30-day stroke and mortality rates as a subanalysis along with other risk factors or between case series there was a significant difference in the association between sex and the combined end-point, even when applying the random-effects model (Peto OR, 1.390; $95 \% \mathrm{CI}$, $1.148-1.684 ; P=.001)$.

When applying the fixed-effects model for the same subset of data, there was a statistically significant difference between the two genders regarding the combined end-point 30-day mortality and stroke rate (Peto OR, 1.400; 95 \% CI, 1.180-1.662; $P<.000)$, as well. Moderate heterogeneity among the studies existed $\left(I^{2}=13.4 \%\right)$, and the likelihood of publication bias was low $(P=.82)$.

\section{Population based databases}

Among the 12 database-studies [10, 11, 35, 39, 63-65, $73,74,80,82,83]$ reporting combined 30 -day stroke and mortality rates as a secondary end-point there was no difference in the association between sex and the combined end-point when applying the random-effects model (Peto OR, 1.025; 95 \% CI, 0.958-1.097; $P=.474$ ) as well as when using the fixed-effects model (Peto OR, 1.022; $95 \% \mathrm{CI}, 0.969-1.079 ; P=.419)$. Low heterogeneity among the studies existed $\left(I^{2}=11.2 \%\right)$, and the likelihood of publication bias was low $(P=.83)$.

\section{RCTs}

Among the 10 RCTs $[1-4,56,58,69,75,86,87]$ reporting combined 30-day stroke and mortality rates as a subanalysis along with other risk factors there was a significant difference in the association between sex and the combined 
Table 1 Baseline characteristics of included studies

First author Study Women Men type (Total N) (Tota Log odds ratio Std Publication Asymptomatic Asymptomatic Dyslipidemia Dyslipidemia Hypertension Hypertension Diabetes (stroke and
mortality rate)

\begin{tabular}{|c|c|c|c|c|c|c|c|c|c|c|c|c|c|}
\hline Schneider 1997 [28] & $\mathrm{CS} / \mathrm{P}$ & 155 & 271 & 0,9887 & 0,6535 & 1997 & 30 & 23 & - & - & 74 & 68 & 16 \\
\hline Rigdon 1998 [29] & $\mathrm{CS} / \mathrm{P}$ & 175 & 254 & 0,6951 & 0,4523 & 1998 & - & - & - & - & - & - & - \\
\hline Akbari 2000 [30] & $\mathrm{CS} / \mathrm{P}$ & 520 & 778 & $-0,2442$ & 0,3948 & 2000 & 51 & 44 & - & - & 77 & 66 & 42 \\
\hline Ballotta 2000 [31] & $\mathrm{CS} / \mathrm{P}$ & 196 & 423 & $-0,4899$ & 0,8064 & 2000 & 35 & 35 & 43 & 46 & 64 & 55 & 48 \\
\hline Sternbach 2000 [33] & $\mathrm{CS} / \mathrm{P}$ & 68 & 88 & 0,2612 & 1,4235 & 2000 & - & - & 47 & 47 & 70 & 69 & 24 \\
\hline Schneider 2000 [32] & $\mathrm{CS} / \mathrm{P}$ & 90 & 492 & $-0,7106$ & 1,0508 & 2000 & - & - & - & - & - & - & - \\
\hline James 2001 [36] & $\mathrm{CS} / \mathrm{P}$ & 125 & 199 & 0,4772 & 0,7165 & 2001 & 51 & 45 & 60 & 56 & 75 & 66 & 21 \\
\hline Mattos 2001 [35] & $\mathrm{CS} / \mathrm{P}$ & 465 & 739 & $-0,9296$ & 0,7927 & 2001 & 33 & 33 & - & - & 66 & 61 & 29 \\
\hline Sarac 2002 [37] & $\mathrm{CS} / \mathrm{P}$ & 1148 & 2274 & 0,4837 & 0,2212 & 2002 & 74 & 74 & - & - & - & - & 23 \\
\hline Lane 2003 [39] & $\mathrm{CS} / \mathrm{P}$ & 115 & 246 & 0,9757 & 0,6164 & 2003 & 50 & 58 & 17 & 29 & 75 & 70 & 17 \\
\hline Lee 2003 [83] & $\mathrm{CS} / \mathrm{P}$ & 600 & 903 & $-0,1240$ & 0,4020 & 2003 & 48 & 45 & 45 & 37 & 77 & 67 & 41 \\
\hline Weise 2004 [84] & $\mathrm{CS} / \mathrm{P}$ & 56 & 156 & 0,5953 & 0,5927 & 2004 & 27 & 26 & 37 & 34 & 70 & 57 & 29 \\
\hline Harthun 2005 [78] & $\mathrm{CS} / \mathrm{P}$ & 5950 & 8144 & 0,3474 & 0,1381 & 2005 & - & - & - & - & 77 & 77 & 8 \\
\hline Hugl 2006 [77] & $\mathrm{CS} / \mathrm{P}$ & 115 & 229 & $-2,6675$ & 1,4444 & 2006 & 84 & 76 & - & - & - & - & - \\
\hline Park 2008 [75] & $\mathrm{CS} / \mathrm{P}$ & 40 & 53 & $-1,3691$ & 1,5633 & 2008 & 52 & 53 & - & - & 93 & 94 & 30 \\
\hline Dorigo 2009 [71] & $\mathrm{CS} / \mathrm{P}$ & 1200 & 2809 & 0,8562 & 0,4097 & 2009 & 66 & 64 & 32 & 27 & 73 & 64 & 22 \\
\hline Poisson 2010 [65] & $\mathrm{CS} / \mathrm{P}$ & 52 & 84 & $-1,1718$ & 1,1100 & 2010 & 69 & 61 & 44 & 53 & 72 & 71 & 25 \\
\hline Yavas 2010 [66] & $\mathrm{CS} / \mathrm{P}$ & 42 & 163 & $-0,7495$ & 1,0751 & 2010 & 38 & 35 & 41 & 22 & 52 & 41 & 21 \\
\hline Baracchini 2012 [61] & $\mathrm{CS} / \mathrm{P}$ & 466 & 992 & 0,2461 & 0,7324 & 2012 & 32 & 36 & 60 & 52 & 66 & 59 & 29 \\
\hline Luebke 2014 [58] & $\mathrm{CS} / \mathrm{P}$ & 588 & 1292 & 0,095 & 0,4113 & 2013 & 78 & 75 & 33 & 39 & 85 & 81 & 22 \\
\hline Guzman 2013 [59] & $\mathrm{CS} / \mathrm{P}$ & 363 & 683 & $-0,1327$ & 0,4624 & 2013 & 33 & 36 & 50 & 52 & 76 & 72 & 23 \\
\hline Friedmann 1988 [40] & $\mathrm{CS} / \mathrm{S}$ & 280 & 408 & $-0,1776$ & 0,3870 & 1988 & - & - & - & - & - & - & - \\
\hline Maxwell 1990 [42] & $\mathrm{CS} / \mathrm{S}$ & 289 & 345 & 0,8866 & 0,6176 & 1990 & - & - & - & - & - & - & - \\
\hline Magnan 1993 [43] & $\mathrm{CS} / \mathrm{S}$ & 90 & 300 & 0,1837 & 0,5354 & 1993 & - & - & - & - & - & - & - \\
\hline Goldstein 1994 [44] & $\mathrm{CS} / \mathrm{S}$ & 256 & 441 & $-0,054$ & 0,2840 & 1994 & - & - & - & - & - & - & - \\
\hline Riles 1994 [41] & $\mathrm{CS} / \mathrm{S}$ & 844 & 1488 & 0,2052 & 0,2541 & 1994 & - & - & - & - & - & - & - \\
\hline Plestis 1996 [45] & $\mathrm{CS} / \mathrm{S}$ & 396 & 610 & 0,8950 & 0,4322 & 1996 & - & - & - & - & - & - & - \\
\hline Hertzer 1997 [46] & $\mathrm{CS} / \mathrm{S}$ & 652 & 1272 & 0,6340 & 0,3162 & 1997 & 60 & 60 & - & - & - & - & - \\
\hline Kerdiles 1997 [47] & $\mathrm{CS} / \mathrm{S}$ & 103 & 178 & $-0,3499$ & 0,4409 & 1997 & - & - & - & - & - & - & - \\
\hline Goldstein II 1998 [80] & $\mathrm{CS} / \mathrm{S}$ & 151 & 312 & 1,2340 & 0,5790 & 1998 & - & - & - & - & - & - & - \\
\hline Karp 1998 [49] & $\mathrm{CS} / \mathrm{S}$ & 910 & 1035 & 0,4606 & 0,2722 & 1998 & - & - & - & - & - & - & - \\
\hline
\end{tabular}


Table 1 Baseline characteristics of included studies (Continued)

\begin{tabular}{|c|c|c|c|c|c|c|c|c|c|c|c|c|c|}
\hline Kucey 1998 [48] & $\mathrm{CS} / \mathrm{S}$ & 434 & 847 & 0,3147 & 0,2342 & 1998 & - & - & - & - & - & - & - \\
\hline Blohme 1999 [50] & $\mathrm{CS} / \mathrm{S}$ & 94 & 178 & $-0,4864$ & 0,5920 & 1999 & - & - & - & - & - & - & - \\
\hline Hartmann 1999 [51] & $\mathrm{CS} / \mathrm{S}$ & 46 & 62 & 0,5700 & 0,7011 & 1999 & - & - & - & - & - & - & - \\
\hline Frawley 2000 [53] & $\mathrm{CS} / \mathrm{S}$ & 312 & 688 & 0,3915 & 0,5315 & 2000 & 5 & 5 & - & - & - & - & - \\
\hline Naylor 2000 [54] & $\mathrm{CS} / \mathrm{S}$ & 171 & 329 & 0,4833 & 0,6130 & 2000 & - & - & - & - & - & - & - \\
\hline Eckstein 2002 [55] & $\mathrm{CS} / \mathrm{S}$ & 45 & 119 & $-0,5647$ & 0,8021 & 2002 & - & - & - & - & - & - & - \\
\hline Dalainas 2007 [76] & $\mathrm{CS} / \mathrm{S}$ & 936 & 2396 & 0,5283 & 0,1894 & 2007 & 29 & 70 & - & - & - & - & - \\
\hline McCrory 1993 [82] & DB & 407 & 753 & 0,055 & 0,2411 & 1993 & - & - & - & - & - & - & - \\
\hline Huber 1998 [81] & DB & 19508 & 27233 & 0,095 & 0,067 & 1998 & - & - & - & - & - & - & - \\
\hline Rockman 2001 [34] & DB & 991 & 1485 & $-0,3863$ & 0,5409 & 2001 & 34 & 30 & - & - & 62 & 54 & 20 \\
\hline Tu 2003 [79] & DB & 2096 & 3942 & 0,038 & 0,1127 & 2003 & - & 31 & - & - & - & 64 & - \\
\hline Kapral 2003 [38] & DB & 2096 & 3942 & 0,060 & 0,1131 & 2003 & 31 & 30 & 37 & 35 & 71 & 61 & 23 \\
\hline Sidawy 2009 [72] & DB & 551 & 817 & $-0,2644$ & 0,1156 & 2009 & 40 & 60 & - & - & - & - & - \\
\hline Halm 2009 (198-1999) [73] & DB & 4125 & 5181 & 0,1419 & 0,1061 & 2009 & - & - & - & - & - & - & - \\
\hline Rockman 2011 [64] & DB & 21621 & 29162 & $-0,037$ & 0,5856 & 2011 & 95 & 95 & - & - & - & - & - \\
\hline Bisdas NYS 2012 [62] & DB & 1969 & 3133 & 0,0676 & 0,1908 & 2012 & 92 & 91 & 45 & 44 & 74 & 71 & 29 \\
\hline Menyhei 2012 [63] & DB & 15358 & 32637 & 0,7540 & 0,5774 & 2012 & 32 & 68 & - & - & - & - & - \\
\hline Jim 2013 [11] & $\mathrm{DB}$ & 2678 & 3814 & 0,0241 & 0,1390 & 2013 & 61 & 58 & - & - & 85 & 83 & 31 \\
\hline Kuy 2014 (NIS DATABASE) [10] & DB & 94404 & 126849 & 0,008 & 0,036 & 2014 & 91 & 90 & - & - & - & - & - \\
\hline ACAS 1995 [1] & $\mathrm{RCT}$ & 281 & 544 & 0,7855 & 0,4654 & 1995 & - & - & - & - & - & - & - \\
\hline ECST 1998 [3] & $\mathrm{RCT}$ & 842 & 1962 & 0,5210 & 0,1932 & 1998 & - & - & - & - & - & - & - \\
\hline NASCET 1998 [4] & $\mathrm{RCT}$ & 424 & 1012 & 0,1660 & 0,2513 & 1998 & - & - & - & - & - & - & - \\
\hline ACE 1999 [57] & $\mathrm{RCT}$ & 842 & 1962 & 0,2067 & 0,1848 & 1999 & - & - & - & - & - & - & - \\
\hline ACST 2004 [2] & RCT & 469 & 936 & 0,4007 & 0,3249 & 2004 & - & - & - & - & - & - & - \\
\hline CAVATAS 2009 [74] & RCT & 75 & 178 & $-0,3873$ & 0,3633 & 2009 & - & - & - & - & - & - & - \\
\hline $\begin{array}{l}\text { EVA-3 s, SPACE, ICSS [56, 69, } \\
87,98]\end{array}$ & $\mathrm{RCT}$ & 476 & 1232 & 0,2746 & 0,2203 & 2010 & - & - & - & - & - & - & - \\
\hline CREST 2013 [87] & $\mathrm{RCT}$ & 417 & 823 & $-0,1214$ & 0,4059 & 2013 & 46 & 48 & 86 & 86 & 86 & 86 & 31 \\
\hline
\end{tabular}


Table 1 Baseline characteristics of included studies (Continued)

\begin{tabular}{|c|c|c|c|c|c|c|c|c|c|c|c|c|c|c|}
\hline First author & $\begin{array}{l}\text { Diabetes } \\
\text { men, \% }\end{array}$ & $\begin{array}{l}\text { PAD } \\
\text { women, } \\
\%\end{array}$ & $\begin{array}{l}\text { PAD } \\
\text { men, } \\
\%\end{array}$ & $\begin{array}{l}\text { CAD } \\
\text { women, } \\
\%\end{array}$ & $\begin{array}{l}\text { CAD } \\
\text { men, } \\
\%\end{array}$ & $\begin{array}{l}\text { Smoker } \\
\text { women, } \\
\%\end{array}$ & $\begin{array}{l}\text { Smoker } \\
\text { men, } \\
\%\end{array}$ & $\begin{array}{l}\text { Age } \\
\text { women, } \\
\%\end{array}$ & $\begin{array}{l}\text { Age } \\
\text { men, } \\
\%\end{array}$ & $\begin{array}{l}\text { Shunt } \\
\text { women, } \\
\%\end{array}$ & $\begin{array}{l}\text { Shunt } \\
\text { men, } \\
\%\end{array}$ & $\begin{array}{l}\text { Redo CEA } \\
\text { women, } \\
\%\end{array}$ & $\begin{array}{l}\text { Redo CEA } \\
\text { men, } \%\end{array}$ & $\begin{array}{l}\text { NOS, } \\
\text { Jadad- } \\
\text { score }\end{array}$ \\
\hline Schneider 1997 [28] & 22 & - & - & 39 & 53 & 59 & 58 & 72 & 71 & 28 & 28 & - & - & \\
\hline Rigdon 1998 [29] & - & - & - & - & - & - & - & - & - & - & - & - & - & \\
\hline Akbari 2000 [30] & 36 & - & - & 40 & 50 & 53 & 68 & 71 & 70 & - & - & - & - & \\
\hline Ballotta 2000 [31] & 30 & 61 & 69 & 17 & 24 & 71 & 62 & 71 & 70 & 13 & 15 & - & - & \\
\hline Sternbach 2000 [33] & 19 & - & - & 13 & 29 & 47 & 60 & 71 & 70 & - & - & - & - & \\
\hline Schneider 2000 [32] & - & - & - & - & - & - & - & - & - & - & - & - & - & \\
\hline James 2001 [36] & 21 & - & - & 10 & 15 & 68 & 74 & 70 & 70 & 71 & 71 & - & - & \\
\hline Mattos 2001 [35] & 23 & - & - & 27 & 39 & 41 & 51 & 69 & 68 & 61 & 61 & - & - & \\
\hline Sarac 2002 [37] & 22 & - & - & 57 & 73 & - & - & 69 & 69 & - & - & 7 & 6 & \\
\hline Lane 2003 [39] & 25 & - & - & 10 & 8 & 58 & 68 & 73 & 71 & 33 & 30 & - & - & \\
\hline Lee 2003 [83] & 36 & 17 & 18 & 40 & 50 & 69 & 84 & 71 & 70 & 79 & 74 & - & - & \\
\hline Weise 2004 [84] & 25 & 18 & 19 & 23 & 22 & - & - & 65 & 64 & - & - & - & - & \\
\hline Harthun 2005 [78] & 6 & - & - & 28 & 40 & - & - & 70 & 70 & - & - & - & - & \\
\hline Hugl 2006 [77] & - & - & - & - & - & - & - & - & - & - & - & - & - & \\
\hline Park 2008 [75] & 23 & - & - & 23 & 17 & 70 & 70 & 70 & 72 & - & - & - & - & \\
\hline Dorigo 2009 [71] & 19 & 25 & 34 & 15 & 23 & 36 & 81 & 72 & 71 & - & - & 3 & 4 & \\
\hline Poisson 2010 [65] & 42 & 10 & 10 & 27 & 40 & 77 & 91 & 76 & 73 & - & - & - & - & \\
\hline Yavas 2010 [66] & 22 & 14 & 31 & 15 & 19 & 12 & 34 & 64 & 65 & 69 & 70 & - & - & \\
\hline Baracchini 2012 [61] & 34 & 53 & 60 & 40 & 45 & 63 & 69 & 76 & 75 & 18 & 14 & - & - & \\
\hline Luebke 2014 [58] & 26 & 24 & 30 & 34 & 45 & 32 & 38 & 76 & 75 & 24 & 17 & - & - & \\
\hline Guzman 2013 [59] & 25 & 25 & 32 & 38 & 47 & 62 & 68 & 71 & 70 & 82 & 79 & 2 & 1 & \\
\hline Friedmann 1988 [40] & - & - & - & - & - & - & - & - & - & - & - & - & - & \\
\hline Maxwell 1990 [42] & - & - & - & - & - & - & - & - & - & - & - & - & - & \\
\hline Magnan 1993 [43] & - & - & - & - & - & - & - & - & - & - & - & - & - & \\
\hline Goldstein 1994 [44] & - & - & - & - & - & - & - & - & - & - & - & - & - & \\
\hline Riles 1994 [41] & - & - & - & - & - & - & - & - & - & - & - & - & - & \\
\hline Plestis 1996 [45] & - & - & - & - & - & - & - & - & - & - & - & - & - & \\
\hline Hertzer 1997 [46] & - & - & - & - & - & - & - & - & - & - & - & - & - & \\
\hline Kerdiles 1997 [47] & - & - & - & - & - & - & - & - & - & - & - & - & - & \\
\hline Goldstein I| 1998 [80] & - & - & - & - & - & - & - & - & - & - & - & - & - & \\
\hline Karp 1998 [49] & - & - & - & - & - & - & - & - & - & - & - & - & - & \\
\hline
\end{tabular}


Table 1 Baseline characteristics of included studies (Continued)

Kucey 1998 [48]

Blohme 1999 [50]

Hartmann 1999 [51]

Frawley 2000 [53]

Naylor 2000 [54]

Eckstein 2002 [55]

Dalainas 2007 [76]

McCrory 1993 [82]

Huber 1998 [81]

Rockman 2001 [34]

Tu 2003 [79]

Kapral 2003 [38]

Sidawy 2009 [72]

Halm 2009 (198-1999) [73]

Rockman 2011 [64]

Bisdas NYS 2012 [62]

Menyhei 2012 [63]

Jim 2013 [11]

Kuy 2014 (NIS DATABASE) [10]

ACAS 1995 [1]

ECST 1998 [3]

NASCET 1998 [4]

ACE 1999 [57]

ACST 2004 [2]

CAVATAS 2009 [74]

EVA-3 S, SPACE, ICSS [56, 69, 87, 98]

CREST 2013 [87]
68

68

Blank

29

32

45

42

40

54

57

63

$-$ 


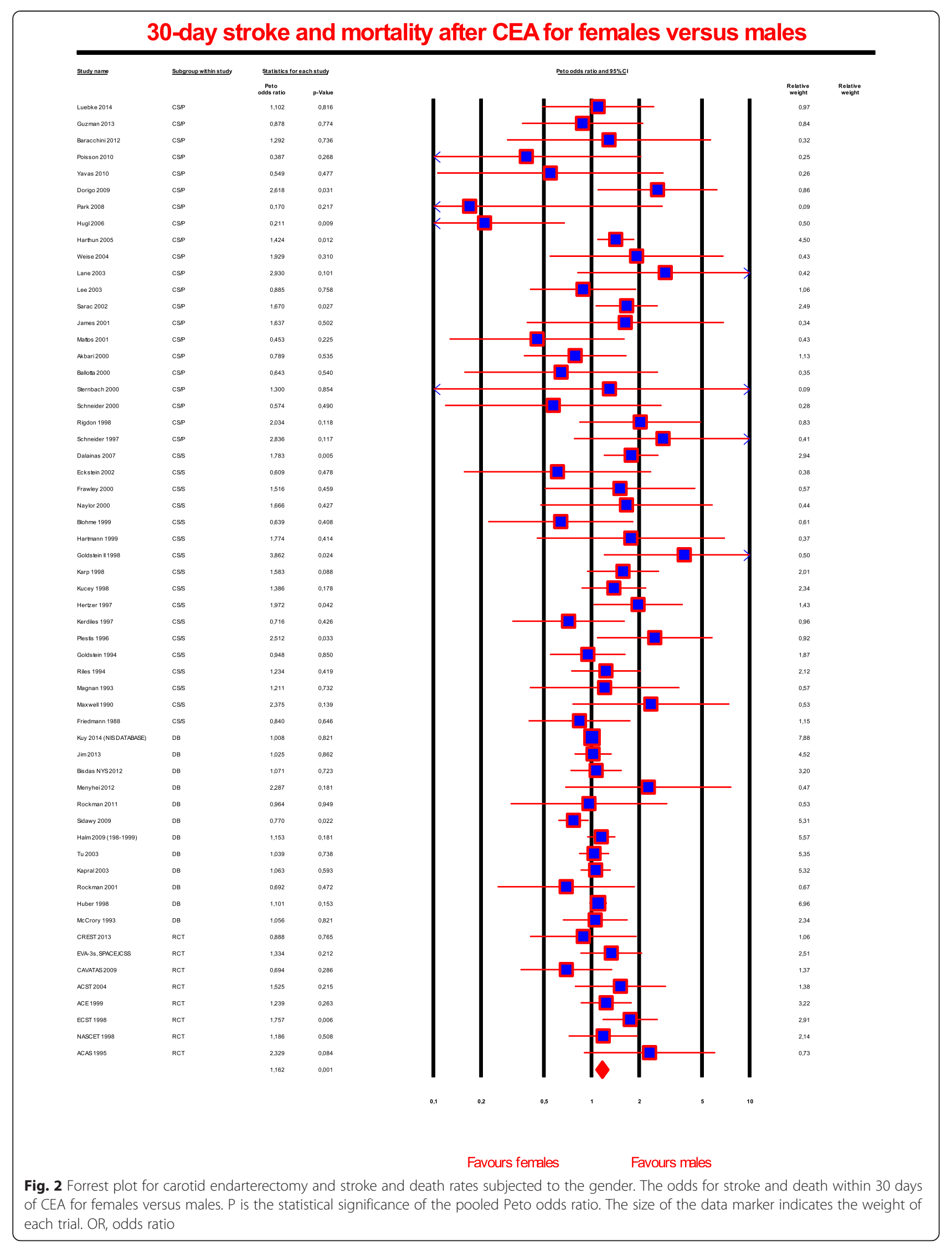




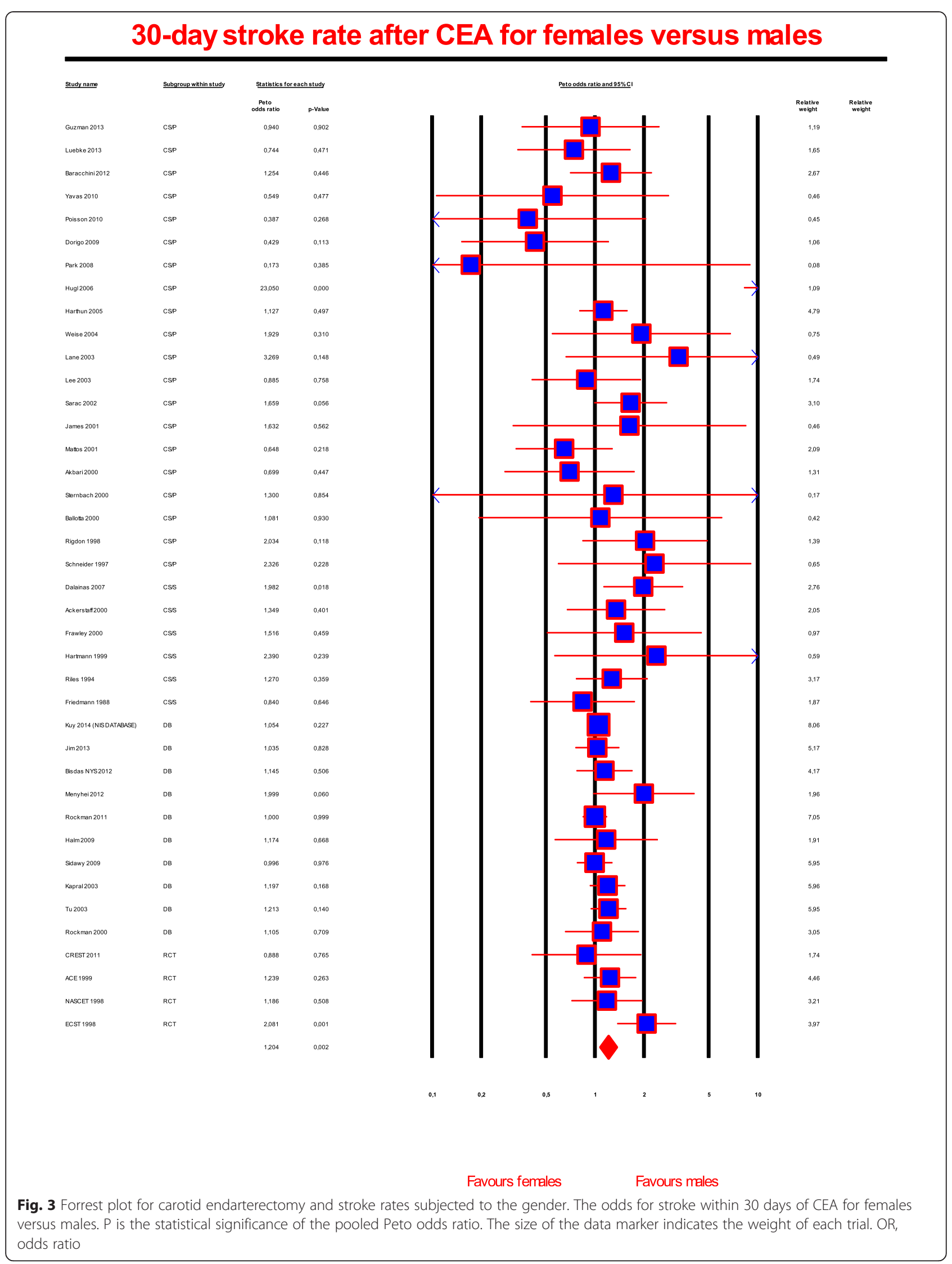


end-point, even when applying the random-effects model (Peto OR, 1.302; $95 \%$ CI, 1.060-1.600; $P=.012$ ).

When applying the fixed-effects model for the same subset of data, there was a statistically significant difference between the two genders regarding the combined end-point 30-day mortality and stroke rate (Peto OR, 1.310; $95 \%$ CI, 1.089-1.576; $P=.004$ ), as well. Low heterogeneity among the studies existed $\left(I^{2}=15 \%\right)$, and the likelihood of publication bias was low $(P=.69)$.

\section{All study types with gender analyses as a secondary aim} When combining all $38[1-4,10,11,35,39,41-52,54-56$, $58,63-65,69,73-75,77,80-83,86,87]$ studies with gender analyses as a secondary aim, random-effects metaanalysis as well as fixed-effects meta-analysis reveal a significant association between sex and the combined endpoint (Peto OR, 1.150; $95 \% \mathrm{CI}, 1.050-1.260 ; P=.003$ and Peto OR, 1.068; 95 \% CI, 1.017-1.123; $P=.009$, respectively). Moderate heterogeneity among the studies existed $\left(I^{2}=36.1 \%\right)$, and the likelihood of publication bias was low $(P=.61)$.

\section{Studies published after the year 2004}

Among the 24 studies [2, 10, 11, 56, 59, 60, 62-67, 69, 72-79, 85-87] published after the year 2004 and reporting combined 30-day stroke and mortality rates there was no difference in the association between sex and the combined end-point when applying the random-effects model (Peto OR, 1.119; $95 \%$ CI, 0.983-1.274; $P=.088$ ) as well as when using the fixed-effects model (Peto OR, 1.043 ; $95 \%$ CI, 0.984-1.105; $P=.155)$. Moderate heterogeneity among the studies existed $\left(I^{2}=45.5 \%\right)$, and the likelihood of publication bias was low $(P=.38)$.

The combined outcome estimate of combined 30-day mortality and stroke rates was not substantially affected when the primary analysis was repeated with a fixedeffects model (OR, 1.084; $95 \% \mathrm{CI}, 1.033-1.137$; $\mathrm{P}=.001$ ), altered data sets after excluding each single study at a time (OR, 1.177; 95 \% CI, 1.076-1.297; $P<.01$ ), or cumulative analysis (OR, 1.177; 95 \% CI, 1.076-1.2879; $P<.01)$.

\section{0-day stroke rate}

\section{Case series - primary aim}

Among the $20[29-32,34,36-38,40,59,60,62,66,67$, $72,76,78,79,84,85]$ studies reporting 30-day stroke rates as their primary aim there was no difference in the association between sex and the end-point when applying the random-effects model (Peto OR, 1.322; $95 \% \mathrm{CI}$, $0.922-1.895 ; P=.129$ ).

However, when applying the fixed-effects model for the same subset of data, there was a statistically significant difference between the two genders regarding the end-point 30-day stroke rate (Peto OR, 1.235; $95 \%$ CI, 1.024-1.490; $P=.027)$. Moderate heterogeneity among the studies existed $\left(I^{2}=63.4 \%\right)$, and the likelihood of publication bias was low $(P=.44)$.

\section{Case series - secondary aim}

Among the 6 studies [41, 42, 52-54, 77] reporting 30-day stroke rates as a subanalysis along with other risk factors or between case series there was a significant difference in the association between sex and the end-point, even when applying the random-effects model (Peto OR, 1.403; $95 \%$ CI, 1.052-1.871; $P=.021$ ).

When applying the fixed-effects model for the same subset of data, there was a statistically significant difference between the two genders regarding the end-point 30-day stroke rate (Peto OR, 1.403; 95 \% CI, 1.052-1.871; $P=.021)$, as well. No heterogeneity among the studies existed $\left(I^{2}=0 \%\right)$, and the likelihood of publication bias was low $(P=.71)$.

\section{Population based databases}

Among the 10 database-studies [10, 11, 35, 39, 63-65, $73,74,80]$ reporting 30 -day stroke rates as a secondary end-point there was no difference in the association between sex and the end-point when applying the randomeffects model (Peto OR, 1.060; 95 \% CI, 0.992-1.133; $P=.086)$ as well as when using the fixed-effects model (Peto OR, 1.060; 95 \% CI, 0.992-1.133; $P=.086$ ). No heterogeneity among the studies existed $\left(I^{2}=0 \%\right)$, and the likelihood of publication bias was low $(P=.12)$.

\section{RCTs}

Among the 4 RCTs $[3,4,58,86]$ reporting 30-day stroke rates as a subanalysis along with other risk factors there was no difference in the association between sex and the end-point, even when applying the random-effects model (Peto OR, 1.364; $95 \%$ CI, 0.979-1.901; $P=.067$ ).

However, when applying the fixed-effects model for the same subset of data, there was a statistically significant difference between the two genders regarding the end-point 30-day stroke rate (Peto OR, 1.398; $95 \% \mathrm{CI}$, $1.106-1.765 ; P=.005)$, as well. Moderate heterogeneity among the studies existed $\left(I^{2}=45.8 \%\right)$, and the likelihood of publication bias was low $(P=.73)$.

\section{All study types with gender analyses as a secondary aim}

When combining all 20 studies [3, 4, 10, 11, 35, 39, 41, 42, $52-54,58,63-65,73,74,77,80,86]$ with gender analyses as a secondary aim, random-effects meta-analysis as well as fixed-effects meta-analysis reveal a significant association between sex and the end-point (Peto OR, 1.140; 95 \% CI, 1.040-1.249; $P=.005$ and Peto OR, 1.096; $95 \%$ CI, 1.029-1.167; $P=.004$, respectively). Low heterogeneity among the studies existed $\left(I^{2}=18.9 \%\right)$, but the likelihood of publication bias was high $(P=.02)$. 


\section{Studies published after the year 2004}

Among the 19 studies [10, 11, 59, 60, 62-67, 72-74, $76-79,85,86]$ published after the year 2004 and reporting 30-day stroke rates there was no difference in the association between sex and the end-point when applying the random-effects model (Peto OR, 1.182; $95 \%$ $\mathrm{CI}, 0.989-1.414 ; P=.066)$. However, when using the fixedeffects model (Peto OR, 1.071; 95 \% CI, 1.002-1.144; $P=.043)$ a significant difference was revealed. Moderate heterogeneity among the studies existed $\left(I^{2}=65.4 \%\right)$, and the likelihood of publication bias was low $(P=.21)$.

The combined outcome estimate of combined 30-day mortality and stroke rates was not substantially affected when the primary analysis was repeated with a fixedeffects model (OR, 1.109; $95 \%$ CI, 1.045-1.177; $P=.001$ ), altered data sets after excluding each single study at a time (OR, 1.216; 95 \% CI, 1.077-1.373; $P=.002$ ), or cumulative analysis (OR, 1.216; $95 \% \mathrm{CI}, 1.077-1.373 ; P=.002)$.

\section{Meta-regression analyses}

Meta-regression analysis investigated potential effects of clinical confounders on perioperative adverse events associated with CEA subjected to the gender.

\section{Year of publication}

Random-effects meta- regression revealed a statistical significant evidence for an association between the log OR for 30-day stroke and mortality and the year of publication $(p=.004)$ (Fig. 4). This underlines that stroke and mortality rates have reduced over time and that there is a significant association (slope coefficient (s.e.) $=-0.01105(0,00344)$, $p=.00127)$.

\section{Mean age}

Details on mean age were available in 24 studies (availability of information: 60 832/468 045 patients, $12.9 \%$ ). Metaregression showed no statistically significant association between mean age and 30-day stroke and mortality (slope coefficient (s.e.) $=0.00972(0.03199), p=.532)$.

\section{Arteria hypertension}

Details on arterial hypertension were available in 23 studies (availability of information: 54 314/468 045 patients, $11.6 \%)$. Metaregression showed no statistically significant association between arterial hypertension and 30-day stroke and mortality (slope coefficient (s.e.) $=0.00310$ (0.00661), $p=.582)$.

\section{Diabetes mellitus}

Details on diabetes mellitus were available in 24 studies (availability of information: 57 736/468 045 patients, $12.3 \%)$. Metaregression showed no statistically significant association between diabetes mellitus and 30-day stroke and mortality (slope coefficient (s.e.) $=-0.01472$ (0.00655), $p=0.482)$.

\section{Coronary artery disease}

Details on coronary artery disease were available in 24 studies (availability of information:56 496/468 045 patients, $12.1 \%)$. Metaregression documented no statistically significant association between coronary artery

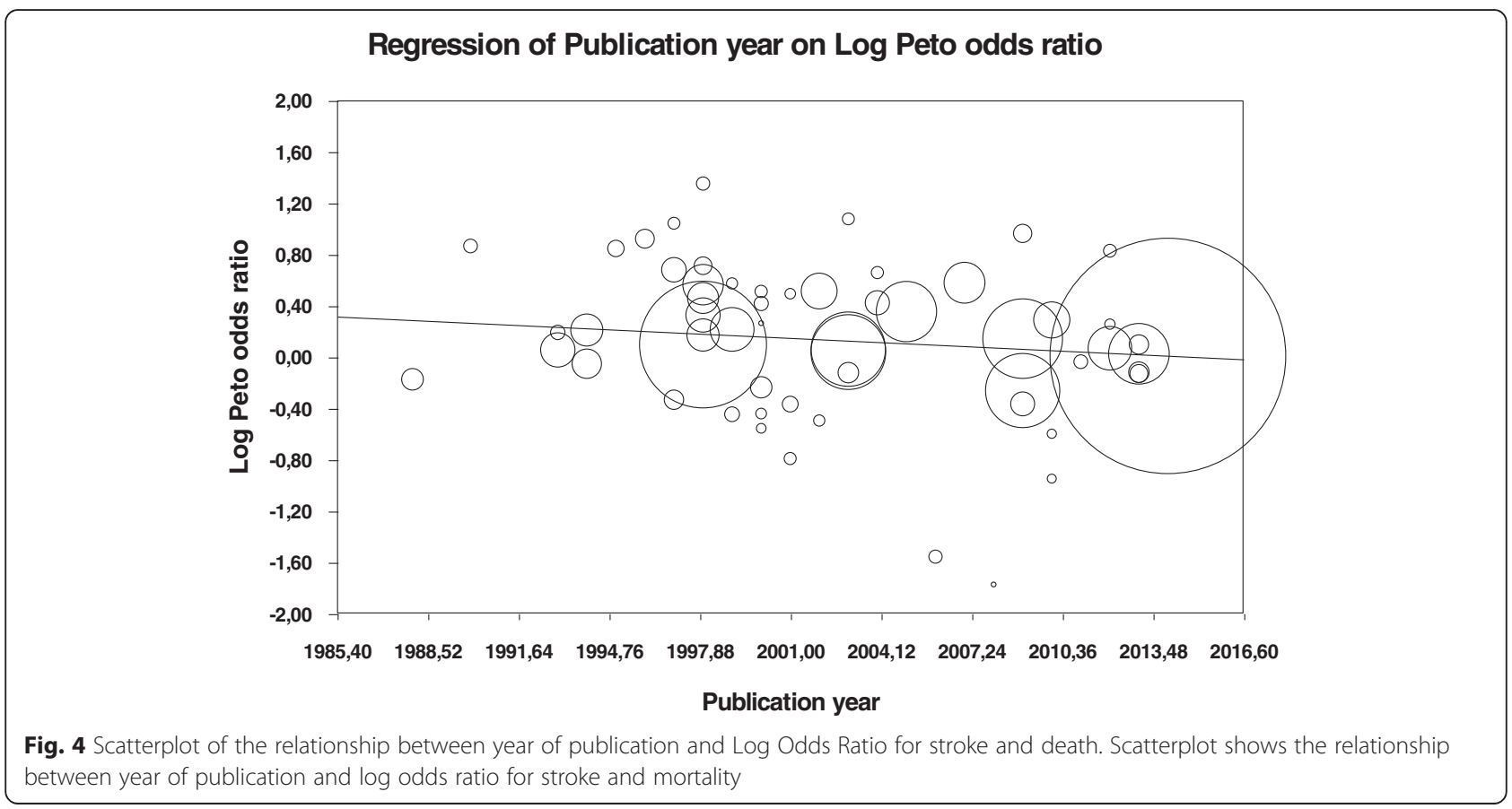


disease and 30-day stroke and mortality (slope coefficient $($ s.e. $)=-0.00134(0.00512), p=0.445)$.

\section{Peripheral arterial disease}

Details on peripheral artery disease were available in 12 studies (availability of information:27 540/468 045 patients, $5.9 \%)$. Metaregression documented no statistically significant association between coronary artery disease and 30-day stroke and mortality (slope coefficient (s.e.) $=-0.00313(0.00932), p=0.726)$.

\section{Dyslipidemia}

Details on dyslipidemia were available in 15 studies (availability of information: 24 289/468 045 patients, $5.2 \%)$. Metaregression showed no statistically significant association between dyslipidemia and 30-day stroke and mortality (slope coefficient (s.e.) $=-0.00691$ (0.00735), $p=0.801)$.

\section{Smoking status}

Details on smoking status were available in 20 studies (availability of information: 34 906/468 045 patients, $7.4 \%)$. Metaregression showed no statistically significant association between smoking status and 30-day stroke and mortality (slope coefficient (s.e.) $=0.00593$ (0.00579), $p=0.677)$.

\section{Symptom status}

Details on symptom status were available in 30 studies (availability of information: 371 485/468 045 patients, $79.4 \%)$. Metaregression showed a statistically significant association between symptom status and 30-day stroke and mortality (slope coefficient (s.e.) $=-0.00049$ (0.00153), $p=0.00893)$.

\section{Quality assessment}

The methodologic quality of the 10 RCTs included in the present meta-analysis, represented in the Jadad score, was low (all studies: Jadad score 3 ). Similarly, only a small proportion of the observational studies achieved a NOS score $>6$ (15 of 58 studies).

\section{TSA for 30-day stroke and mortality rate}

For the outcome of 30-day death or stroke, the required diversity was calculated based on an RRI of $20 \%$, alpha of $5 \%$, and beta of $20 \%$.

\section{Studies published after the year 2004}

The cumulative $\mathrm{z}$ curve crossed both the traditional boundary and the TSMB for the outcomes of death or stroke, demonstrating firm evidence for a $20 \%$ RRI in the female group compared with the male group (Fig. 5).

\section{Case series - primary aim}

The cumulative $\mathrm{z}$ curve crossed the traditional boundary but not the TSMB, suggesting a lack of firm evidence for an RRI of $20 \%$ in the female group compared with the male group (Fig. 6).

\section{Case series - secondary aim}

The cumulative $\mathrm{z}$ curve crossed the traditional boundary but not the TSMB, suggesting a lack of firm evidence for an RRI of $20 \%$ in the female group compared with the male group (Fig. 7).

\section{RCTs}

The cumulative $\mathrm{z}$ curve crossed the traditional boundary but not the TSMB, suggesting a lack of firm evidence for an RRI of $20 \%$ in the female group compared with the male group.

\section{Discussion}

Gender-based outcomes and the etiology of sex-related mechanisms in patients treated with CEA are a topic of considerable debate in the recent vascular literature [34, $35,38,39,64,71,77,88]$. Till now, there are no generally accepted and obliging guidelines regarding the preoperative selection of CEA patients subjected to the gender $[59,89,90]$.

\section{RCT data}

Subgroup analysis of the large CEA-randomised trials have suggested that the benefit from CEA would be less in women compared to men for both, symptomatic and asymptomatic carotid stenosis. In particular, in the European Carotid Surgery Trial (ECST) and the Asymptomatic Carotid Surgery Trial (ACST) women appeared to have higher risks of perioperative complications, and in the moderate (50\% to $69 \%$ ) stenosis arm of the North American Symptomatic Carotid Endarterectomy Trial (NASCET) women did not appear to benefit from surgery at all. In this subset of female patients CEA was associated with a marginal or reduced long-term benefit combined with at least 2-fold increase in the perioperative complication rate as compared to men. It has been hypothesized, that the lower degree of benefit in women was caused partly by a (slightly) higher operative risk in combination with a lower natural history risk of stroke in women as compared to men [5-7]. However, these assumptions are based on post-hoc subgroup analyses on results of these RCTs and have therefore some inherent limitations. Women comprised only a third of patients in these trials (between 28 and $34 \%$ ) and this relatively small sample size has left them underpowered to detect important differences between women and men. In addition to that, selection criteria for these randomized 


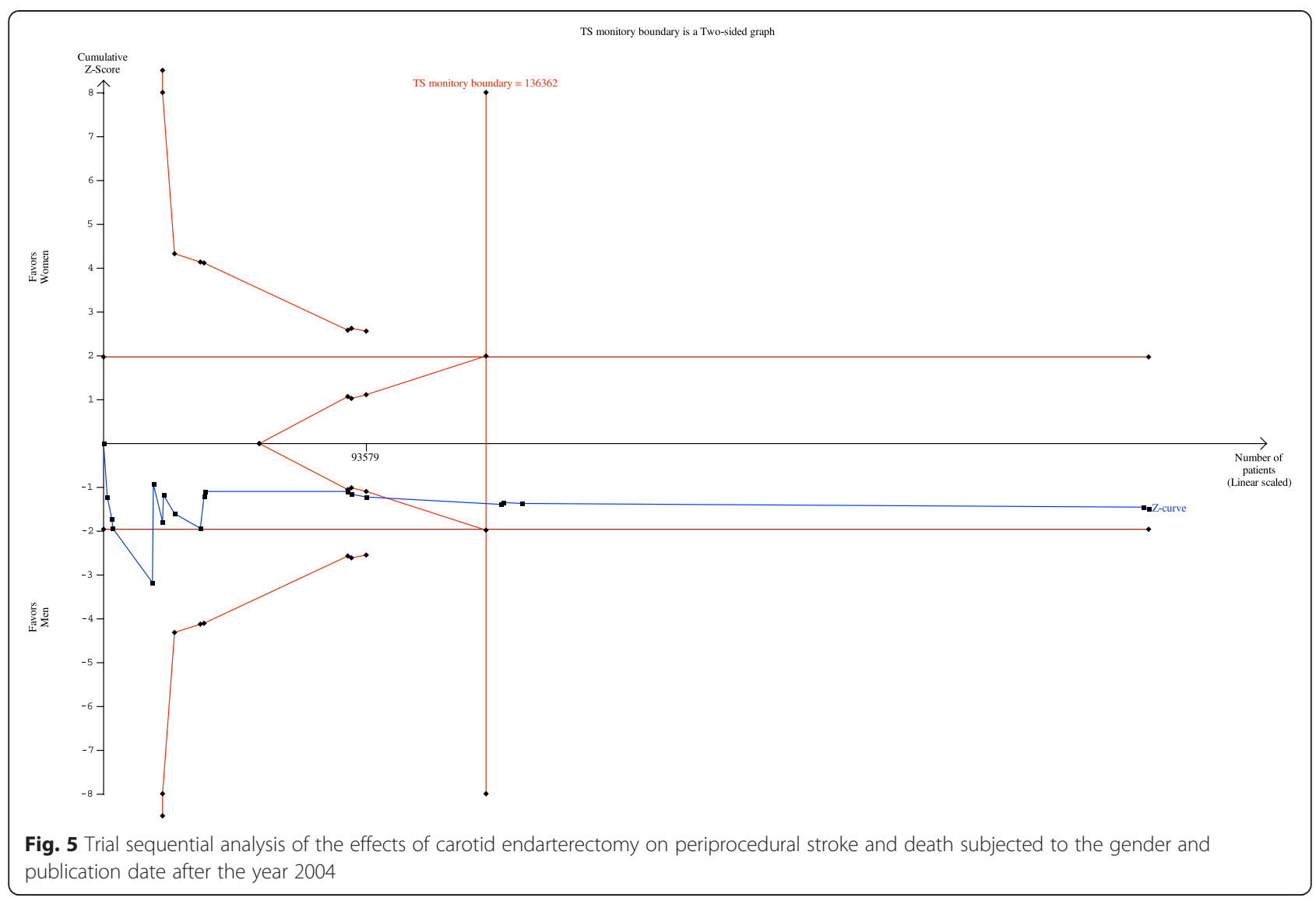

controlled trials may partly explain the discrepant findings and thus limiting their generalizability to the typical endarterectomy population. As a result, these genderrelated results are difficult to interpret due to significant design limitations [5] and due to a lack of adjustment for other important prognostic factors. In the recently published International Carotid Stenting Study (ICSS), women had a higher 120-day event rate for CEA compared to men (7.6\% vs $4.2 \%)$ [91]. On the contrary, in the Carotid Revascularization Endarterectomy vs Stenting Trial (CREST), women undergoing CEA had a lower periprocedural event rate compared to men ( $3.8 \%$ vs $4.9 \%$ ) [87].

The present unselected meta-analysis of RCTs revealed that female patients undergoing CEA had a higher combined risk of death and stroke after the intervention than did male patients (Peto OR, 1,162; 95 \% CI, 1.067-1.266; $P=.001$ ). We analyzed the robustness of the observed outcomes by performing sensitivity analyses. Low heterogeneity among the studies existed $\left(I^{2}=15 \%\right)$, and the likelihood of publication bias was low $(P=.69)$. In the TSA, the cumulative $\mathrm{z}$ curve crossed the traditional boundary but not the TSMB, suggesting a lack of firm evidence for an RRI of $20 \%$ in the female group compared with the male group in RCTs for the endpoint under investigation. As a result, the higher perioperative risk of stroke and death after CEA in women observed in large RCTs is likely to be a statistical artifact due to small female patient numbers. In addition to that, because of low absolute difference between the gender related outcomes (Peto OR, 1,162; 95 \% CI, 1.067-1.266; $P=.001$ ), the clinical significance of this finding is unclear. As well, we found a significant difference in overall perioperative stroke rates for CEA when men were compared with women (Peto OR, 1.204; 95 \% CI, 1.0731.351; $P=.002$ ). Sensitivity analysis revealed that there might be a statistically significant difference between the two genders regarding the end-point 30-day stroke rate by using the fixed-effects model, as well (Peto OR, 1.398; $95 \%$ CI, 1.106-1.765; $P=.005)$, but again the clinical significance of this small difference may be narrow. In this sensitivity analysis, even moderate heterogeneity among the studies existed $\left(I^{2}=45.8 \%\right)$ but the likelihood of publication bias was low $(P=.73)$.

It has also been suggested that the RCT results may be confounded by referral bias [86]. Women are less likely than men to be selected for both, cardiac and peripheral vascular surgery [92] and recent studies have demonstrated that women are less likely to receive CEA or angioplasty than men in the same situation [86]. Therefore, it might be possible that those women who actually 


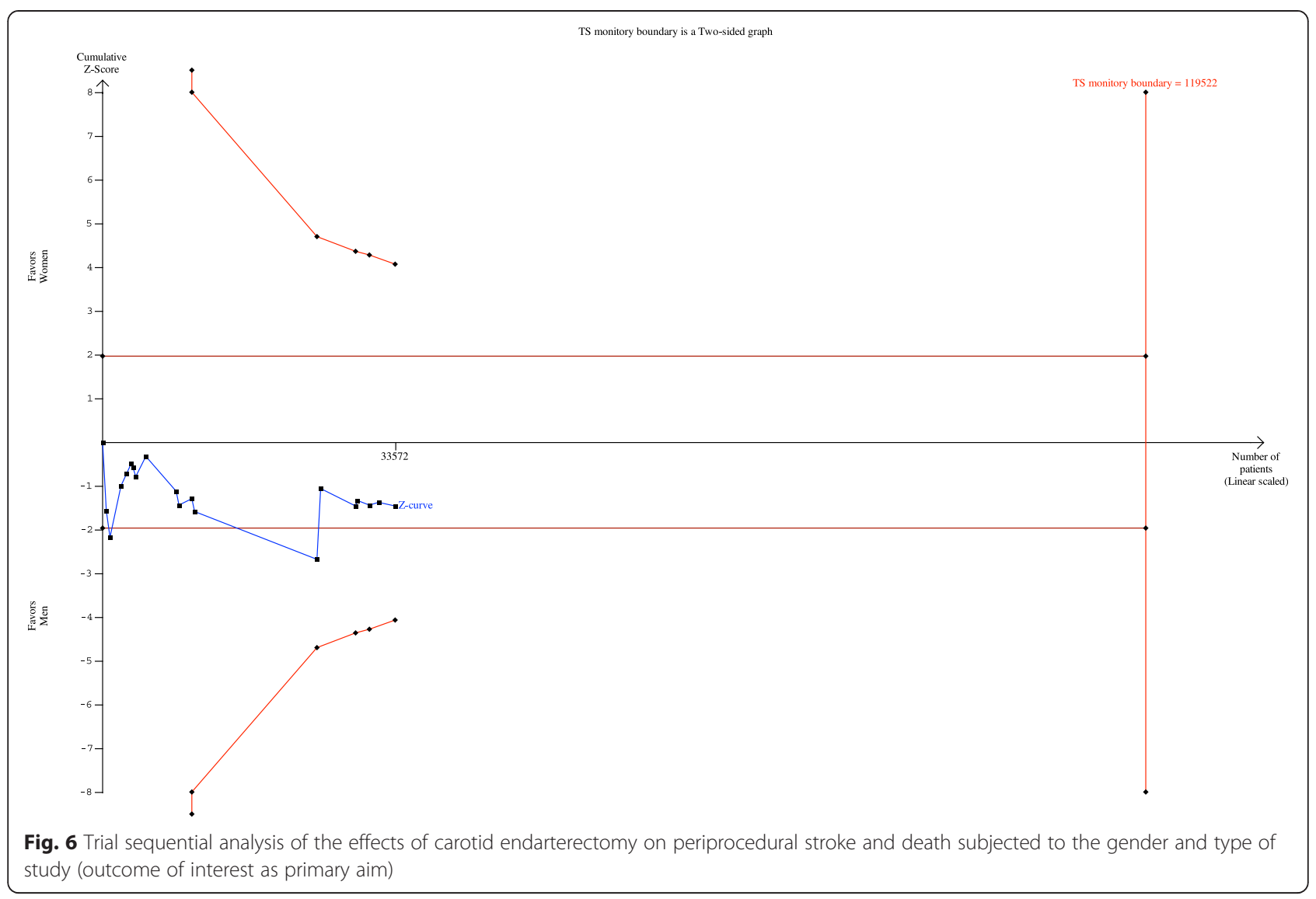

undergo surgery are at higher risk of complications than those who do not. As a result, it is unclear whether these RCT results can be generalised to the non-trial setting $[93,94]$. It is therefore essential to analyze whether the RCT results of CEA are also seen in routine clinical practice.

\section{Non-RCT data \\ Sex related differences as a primary aim of the study}

The case series reporting combined 30-day stroke and mortality rates subjected to the sex as their primary aim found CEA as safe and beneficial in women as in men when applying the random-effects model (Peto OR, 1.202; $95 \%$ CI, 0.925-1.561; $P=.168$ ). However, when applying the fixed-effects model for the same subset of data, there was a statistically significant difference between the two genders regarding the combined endpoint 30-day mortality and stroke rate (Peto OR, 1.299; $95 \%$ CI, 1.089-1.548; $P=.004)$. Moderate heterogeneity among the studies existed $\left(I^{2}=32.9 \%\right)$, and the likelihood of publication bias was low $(P=.23)$. However, in TSA the cumulative $\mathrm{z}$ curve crossed the traditional boundary but not the TSMB, suggesting a lack of firm evidence for an RRI of $20 \%$ in the female group compared with the male group in case series for the endpoint under investigation and gender differences as their primary aim. Thus, although those studies have shown no difference in perioperative stroke and mortality between men and women in the random effects model, criticism may be pointed to the size and power of those studies, raising the possibility of a type II error as demonstrated by TSA. The same was true when analyzing the endpoint 30-day stroke in case series with sex-related differences as a primary aim, with no difference in the association between sex and the end-point when applying the random-effects model (Peto OR, 1.322; 95 \% CI, 0.922-1.895; $P=.129$ ), but a statistically significant difference between the two genders regarding the end-point 30-day stroke rate when applying the fixed-effects model (Peto OR, 1.235; $95 \%$ CI, 1.024$1.490 ; P=.027)$. Moderate heterogeneity among the studies existed $\left(I^{2}=63.4 \%\right)$, and the likelihood of publication bias was low $(P=.44)$.

\section{Sex-related differences as a secondary aim of the study}

The case series reporting combined 30-day stroke and mortality rates subjected to the gender as a secondary aim suggest that CEA is associated with significantly increased risk for periprocedural death and stroke in women when compared with men when applying the randomeffects model and the fixed-effects model, respectively 


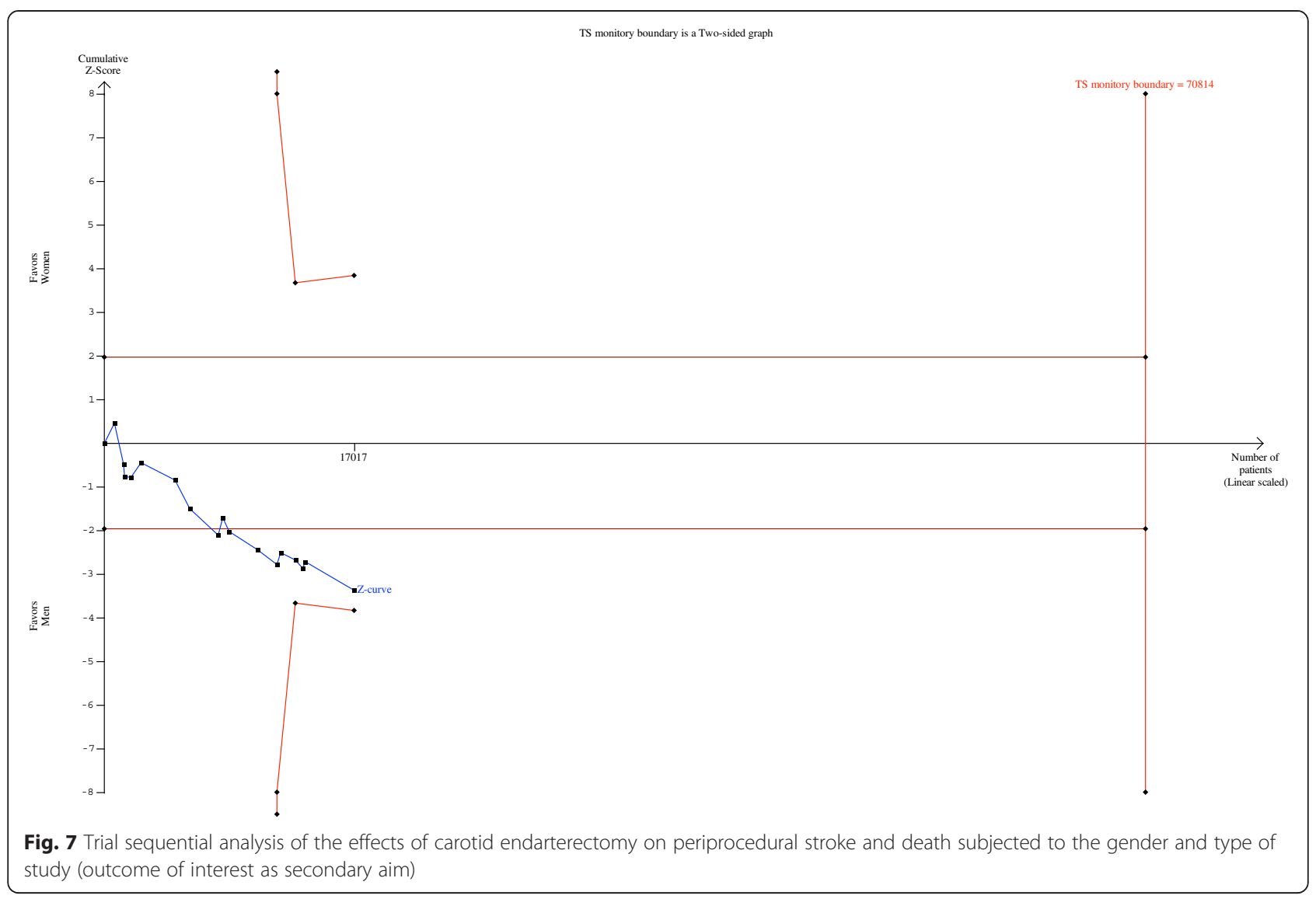

(Peto OR, 1.390; $95 \%$ CI, 1.148-1.684; $P=.001$, and Peto OR, 1.400; $95 \%$ CI, 1.180-1.662; $P<.000$, respectively). Moderate heterogeneity among the studies existed $\left(I^{2}=\right.$ $13.4 \%)$, and the likelihood of publication bias was low $(P=.82)$. However, the cumulative $\mathrm{z}$ curve crossed the traditional boundary but not the TSMB, suggesting a lack of firm evidence for an RRI of $20 \%$ in the female group compared with the male group in case series for the endpoint under investigation and gender differences as a secondary aim. Thus, although those studies have shown a difference in perioperative stroke and mortality between men and women in the randomeffects and the fixed effects model, criticism may be pointed to the size and power of those studies, raising the possibility of a type II error as demonstrated by TSA. The same was true when analyzing the endpoint 30-day stroke in case series with gender differences as a secondary aim, with a significant difference in the association between sex and the end-point when applying the random-effects model (Peto OR, 1.403; $95 \% \mathrm{CI}$, $1.052-1.871 ; P=.021$ ) and the fixed-effects model (Peto OR, 1.403; $95 \%$ CI, 1.052-1.871; $P=.021)$, as well. No heterogeneity among the studies existed $\left(I^{2}=0 \%\right)$, and the likelihood of publication bias was low $(P=.71)$.

\section{Databases}

We found no difference in overall perioperative stroke rates and combined death and stroke rates for CEA when men were compared with women in database analyses. In extensive sensitivity analyses, we demonstrated the robustness of all observed outcomes under investigation. Low heterogeneity among the studies existed, and the likelihood of publication bias was low for all comparisons. Although registries and state-wide databases lack the granular details of patient demographics, comorbidities and procedure preferences, they represent large diverse populations without the institutional selection bias. Therefore, presumably, these databases reflect routine real-world medical practice as compared to databases from randomised controlled trials that usually include tertiary care and university centres only with carefully defined patient selection criteria and practitioner credentialing. These findings probably suggest that medical, daily, population wide practice is rather different from that in large centres.

\section{Metaregression}

Meta-regression analysis investigated potential effects of publication date of each study, age, hypertension, diabetes 
mellitus, coronary artery disease, peripheral artery disease, dyslipidemia, smoking status, and symptomatic or asymptomatic carotid disease on perioperative adverse events associated with CEA subjected to the gender. An interesting finding of the meta-regression analysis is that only the category "year of publication" and "symptom status" were significant confounders for the log odds ratio for stroke and mortality in male and female CEA patients. This essentially means that in older studies, the difference in stroke or mortality is large, becoming less as the years pass, and this reduction in difference is statistically significant. These results are in concordance with the study by Rockman et al. [64]. When stratified by the presence of preoperative symptoms, asymptomatic male and female patients undergoing carotid intervention had a nearly identical rate of postoperative stroke and in-hospital death. However, symptomatic women undergoing carotid artery interventions had a significantly higher rate of postoperative stroke than symptomatic men $(3.8 \%$ vs $2.3 \%, P=.03)$. The clinical significance of this finding is unclear. It is possible, of course, that symptomatic female patients would be at a higher risk for future stroke if no intervention were performed and still benefit from intervention vs medical management.

\section{Own results}

A former meta-analysis of the existing literature performed in 2005 by Bond et al. [95] found that women undergoing CEA did have a higher rate of operative stroke and death than men (odds ratio, 1.31; $95 \%$ confidence interval, 1.17-1.47, $P<.001)$. In the present metaanalysis, the effect of sex on the operative risk of CEA in case series was consistent with those observed in the RCTs. Given the potential concerns about the generalisability of observations made in trials to routine clinical practice, it was important to determine whether the increased operative risk of stroke and death in women observed in the trials of CEA were likely to be seen in routine clinical practice. In contrast to the results presented by Bond et al. [95], we have shown that the effects of sex on the operative risk of CEA in published series from routine clinical practice are not consistent with those observed in the RCTs and even differ between cases series with gender considerations as primary aim and those with gender aspects as a secondary aim and database analyses. Whereas the unselected overall meta-analysis, and the meta-analysis of case series with gender aspects as a secondary outcome showed a significantly increased risk for 30-day stroke and death in women compared to men, meta-analysis of databases and case series with sex-related outcomes as a primary aim demonstrated no increase in operative risk of stroke and death in women compared to men. As a result, the findings of reports in which the gender association was the primary subject of study were highly consistent with those in large databases in which the gender observations was one of many associations reported. Our unselected analysis found significant differences in overall stroke and mortality outcomes between women and men after CEA. In addition, there were also a differences found in stroke and mortality among asymptomatic and symptomatic patients from both sexes. These results do not support the generalisability of the analyses of the overall effects of CEA from the unselected study data to routine clinical practice.

Over the decades 1980 and 2015 optimal medical treatment has been changed tremendously. There is moderate strength of evidence among three quality-A randomized controlled trials (RCTs) (the Veterans Affairs Cooperative Study [VA], the Asymptomatic Carotid Atherosclerosis Study (ACAS), and the Asymptomatic Carotid Atherosclerosis Trial [ACST]) that carotid endarterectomy (CEA) and best medical therapy (BMT) can reduce the risk of ipsilateral stroke as compared with best medical therapy alone, which was demonstrated by all three trials. However, the results from these trials are not applicable to contemporary clinical practice, as they do not compare CEA with contemporary best medical therapy and under conditions of real-world adherence and persistence, respectively. Surgeons in contemporary clinical trials with up-to-date best medical treatment have also achieved CEA periprocedural death and stroke rates lower than those in pivotal trials. For example, in the Carotid Revascularization Endarterectomy vs. Stenting Trial (CREST), the death/stroke rates for symptomatic patients was $3.2 \%$ and for asymptomatic patients was $1.4 \%$. To date, there is no RCT that has analysed the impact of contemporary best medical treaetment of carotid artery stenosis subjected to the sex as a primary aim of the study.

In the present study, among the 24 studies $[2,10,11$, $56,59,60,62-67,69,72-79,85-87]$ published after the year 2004 with a contemporary best medical treatment and reporting combined 30-day stroke and mortality rates there was no difference in the association between sex and the combined end-point when applying the random-effects model as well as when using the fixedeffects model. In addition to that, TSA showed that confidence can be put into these results. Although, the studies published after the year 2004 represent a more contemporary management of patients with carotid artery stenosis, the interpretation of these results regarding the impact of best medical treatment alone on these sexstratified outcomes should be done with caution.

\section{Possible reasons for gender differences}

The reasons for the postulated perioperative risk difference remain speculative and the overall evidence for outcome differences by sex-specific characteristics is limited 
in the literature. Potential explanations for higher surgical risks in women include the older age of onset of cerebrovascular disease in women [96]. Other explanations for the sex disparities in benefit from CEA may be attributed to further reasons listed in Table 2 [97-105].

\section{Limitations}

Although we believe that our results are likely to be valid, our study does have some potential shortcomings. First, the studies included in the review were of varying methodological quality. Some were retrospective and only a minority of the remainder had independent assessment of outcome by a neurologist. However, although the absolute operative risk will therefore have been underestimated in some studies, this should not have biased the within-study relative odds of stroke and death due to surgery by sex. However, the reliability of the metaanalyses of the within-study comparisons is supported by the consistent results, with very little statistical heterogeneity between studies, in the present review. The same argument applies to the fact that the use of ancillary treatments, such as the use of patching, shunting or local anaesthetic, will also have varied between studies. Secondly, publication bias is a potential problem with analyses of published data. It is possible that some of the studies looked at the interaction of several risk factors with operative risk, but only published those that were 'interesting' or statistically significant. However, funnel plots did not show any obvious skewing suggestive of publication bias (data not shown) and the lack of heterogeneity between studies indicates that selective reporting of extreme results (either associations with low operative risk or high operative risk) was uncommon. Adequate power is difficult to achieve in institutional or even multicenter studies to make meaningful comparisons of rare events, but our analysis has an advantage in that a large patient cohort was used to calculate pooled outcome estimates, such as mortality and stroke. As in other meta-analyses, given the lack of data in each trial, we did not adjust our analyses for medications used during and following the procedure. Although detailed sensitivity analyses on many variables were undertaken, given heterogeneity in the study protocols, clinically relevant differences could have been missed and are best assessed in a meta-analysis of individual patient data. The subgroup analyses might suffer from multiple testing. As a result, the results of the sensitivity analyses are best described as secondary and hypothesis generating only. In addition to that, our report is limited by the heterogeneous groups of patients entering the meta- analysis models. No adjustments for differences in clinical characteristics of the study populations, such as presenting symptom status and atherosclerotic comorbidity, could be made. Further more, each of these studies reported the results of operations performed by multiple surgeons and, in the latter case, in multiple institutions. As a result, there was no standardization of the surgical approach with respect to the method of anesthesia, the use and method of cerebral monitoring, the use of an indwelling shunt, closure of the arteriotomy with a patch, and other factors. These variables were also not controlled

Table 2 Possible reasons for gender differences for carotid endarterectomy

\begin{tabular}{ll}
\hline \multicolumn{1}{l}{ Possible reasons for gender differences } \\
\hline $\begin{array}{l}\text { Plaque } \\
\text { characteristics }\end{array}$ & Older age of onset of cerebrovascular disease in women \\
& Higher rates of carotid artery stenosis, \\
& Lower and more stable plaque burden for the same degree of carotid artery stenosis in females compared with males \\
[natomy & [97]
\end{tabular}


in the ACAS [5] and could potentially confound an analysis of the impact of gender on surgical outcome.

\section{Conclusions}

In conclusion, we have shown that the effects of sex on the operative risk of CEA in published series from routine clinical practice are not consistent with those observed in the RCTs and even differ between cases series with gender considerations as primary aim and those with gender aspects as a secondary aim and database analyses. Whereas the unselected overall meta-analysis, and the meta-analysis of case series with gender aspects as a secondary outcome showed a significantly increased risk for 30-day stroke and death in women compared to men, meta-analysis of databases and case series with gender related outcomes as a primary aim demonstrated no increase in operative risk of stroke and death in women compared to men. This highlights the need for more sex-specific trials that will provide solid information regarding the management of carotid disease in women, define procedural indications for different risk groups, and provide clear guidelines for the community.

\section{Competing interests}

The authors declare that they have no competing interests.

\section{Authors' contributions}

TL contributed to conception and design of the study, analyzed and interpreted the data, wrote and drafted the manuscript and decided to submit the manuscript for publication. JB was involved in drafting the manuscript and in revising it critically for important intellectual content. Both authors read and approved the final manuscript.

Received: 16 February 2015 Accepted: 21 April 2015

Published online: 09 May 2015

\section{References}

1. Endarterectomy for asymptomatic carotid artery stenosis. Executive Committee for the Asymptomatic Carotid Atherosclerosis Study. JAMA. 1995;273(18):1421-8

2. Halliday A, Mansfield A, Marro J, Peto C, Peto R, Potter J, et al. Prevention of disabling and fatal strokes by successful carotid endarterectomy in patients without recent neurological symptoms: randomised controlled trial. Lancet. 2004;363(9420):1491-502. doi:10.1016/S0140-6736(04)16146-1.

3. Randomised trial of endarterectomy for recently symptomatic carotid stenosis: final results of the MRC European Carotid Surgery Trial (ECST) Lancet. 1998;351(9113):1379-87.

4. North American Symptomatic Carotid Endarterectomy Trial. Methods, patient characteristics, and progress. Stroke. 1991;22(6):711-20.

5. Chambers BR, Donnan GA. Carotid endarterectomy for asymptomatic carotid stenosis. Cochrane Database Syst Rev. 2005;4:CD001923. doi:10.1002/14651858.CD001923.pub2

6. Rerkasem K, Rothwell PM. Carotid endarterectomy for symptomatic carotid stenosis. Cochrane Database Syst Rev. 2011;4:CD001081. doi:10.1002/ 14651858.CD001081.pub2.

7. Chambers BR, You RX, Donnan GA. Carotid endarterectomy for asymptomatic carotid stenosis. Cochrane Database Syst Rev. 2000(2):CD001923. doi:10.1002/14651858.CD001923.

8. Licht RW, Gouliaev G, Vestergaard P, Frydenberg M. Generalisability of results from randomised drug trials. A trial on antimanic treatment. Br J Psychiatry. 1997;170:264-7.

9. Gurwitz $J \mathrm{H}, \mathrm{Col} N \mathrm{NF}$, Avorn J. The exclusion of the elderly and women from clinical trials in acute myocardial infarction. JAMA. 1992;268(11):1417-22.
10. Kuy S, Dua A, Desai SS, Rossi PJ, Seabrook GR, Lewis BD, et al. Carotid endarterectomy national trends over a decade: does sex matter? Ann Vasc Surg. 2014;28(4):887-92. doi:10.1016/j.avsg.2013.08.016.

11. Jim J, Dillavou ED, Upchurch Jr GR, Osborne NH, Kenwood CT, Siami FS, et al. Gender-specific 30-day outcomes after carotid endarterectomy and carotid artery stenting in the Society for Vascular Surgery Vascular Registry. J Vasc Surg. 2014;59(3):742-8. doi:10.1016/j.jvs.2013.09.036.

12. Huber TS, Durance PW, Kazmers A, Jacobs LA. Effect of the Asymptomatic Carotid Atherosclerosis Study on carotid endarterectomy in Veterans Affairs medical centers. Arch Surg. 1997;132(10):1134-9.

13. Hannan EL, Popp AJ, Tranmer B, Fuestel P, Waldman J, Shah D. Relationship between provider volume and mortality for carotid endarterectomies in New York state. Stroke. 1998;29(11):2292-7.

14. O'Neill L, Lanska DJ, Hartz A. Surgeon characteristics associated with mortality and morbidity following carotid endarterectomy. Neurology. 2000;55(6):773-81.

15. Wennberg DE, Lucas FL, Birkmeyer JD, Bredenberg CE, Fisher ES. Variation in carotid endarterectomy mortality in the Medicare population: trial hospitals, volume, and patient characteristics. JAMA 1998;279(16):1278-81.

16. Lo CK, Mertz D, Loeb M. Newcastle-Ottawa Scale: comparing reviewers' to authors' assessments. BMC Med Res Methodol. 2014;14:45. doi:10.1186/1471-2288-14-45.

17. Jadad AR, Moore RA, Carroll D, Jenkinson C, Reynolds DJ, Gavaghan DJ, et al. Assessing the quality of reports of randomized clinical trials: is blinding necessary? Control Clin Trials. 1996;17(1):1-12.

18. Sweeting MJ, Sutton AJ, Lambert PC. What to add to nothing? Use and avoidance of continuity corrections in meta-analysis of sparse data. Stat Med. 2004;23(9):1351-75. doi:10.1002/sim.1761

19. Bradburn MJ, Deeks JJ, Berlin JA, Russell Localio A. Much ado about nothing: a comparison of the performance of meta-analytical methods with rare events. Stat Med. 2007;26(1):53-77. doi:10.1002/sim.2528.

20. Moher D, Cook DJ, Eastwood S, Olkin I, Rennie D, Stroup DF. Improving the quality of reports of meta-analyses of randomised controlled trials: the QUOROM statement. Quality of Reporting of Meta-analyses. Lancet. 1999:354(9193):1896-900.

21. Altman DG, Bland JM. Interaction revisited: the difference between two estimates. BMJ. 2003:326(7382):219.

22. Galbraith RF. A note on graphical presentation of estimated odds ratios from several clinical trials. Stat Med. 1988;7(8):889-94.

23. Egger M, Davey Smith G, Schneider M, Minder C. Bias in meta-analysis detected by a simple, graphical test. BMJ. 1997:315(7109):629-34.

24. Begg CB, Berlin JA. Publication bias and dissemination of clinical research. J Natl Cancer Inst. 1989:81(2):107-15.

25. Higgins JP, Thompson SG. Controlling the risk of spurious findings from meta-regression. Stat Med. 2004;23(11):1663-82. doi:10.1002/sim.1752.

26. Brok J, Thorlund K, Gluud C, Wetterslev J. Trial sequential analysis reveals insufficient information size and potentially false positive results in many meta-analyses. J Clin Epidemiol. 2008;61(8):763-9. doi:10.1016/ j.jclinepi.2007.10.007.

27. Wetterslev J, Thorlund K, Brok J, Gluud C. Trial sequential analysis may establish when firm evidence is reached in cumulative meta-analysis. J Clin Epidemiol. 2008;61(1):64-75. doi:10.1016/j.jclinepi.2007.03.013.

28. Schneider JR, Droste JS, Golan JF. Carotid endarterectomy in women versus men: patient characteristics and outcomes. J Vasc Surg. 1997;25(5):890-6. discussion 7-8.

29. Rigdon EE. Racial and gender differences in outcome after carotid endarterectomy. Am Surg. 1998;64(6):527-30. discussion 30-2.

30. Akbari CM, Pulling MC, Pomposelli Jr FB, Gibbons GW, Campbell DR, Logerfo FW. Gender and carotid endarterectomy: does it matter? J Vasc Surg. 2000;31(6):1103-8. discussion 8-9.

31. Ballotta E, Renon L, Da Giau G, Sarzo G, Abbruzzese E, Saladini M, et al. Carotid endarterectomy in women: early and long-term results. Surgery. 2000;127(3):264-71.

32. Schneider JR, Droste JS, Schindler N, Golan JF. Carotid endarterectomy in octogenarians: comparison with patient characteristics and outcomes in younger patients. J Vasc Surg. 2000;31(5):927-35. doi:10.1067/ mva.2000.106417.

33. Sternbach $Y$, Perler BA. The influence of female gender on the outcome of carotid endarterectomy: a challenge to the ACAS findings. Surgery. 2000;127(3):272-5. doi:10.1067/msy.2000.104120. 
34. Rockman CB, Castillo J, Adelman MA, Jacobowitz GR, Gagne PJ, Lamparello $\mathrm{PJ}$, et al. Carotid endarterectomy in female patients: are the concerns of the Asymptomatic Carotid Atherosclerosis Study valid? J Vasc Surg. 2001:33(2):236-40. doi:10.1067/mva.2001.111804. discussion 40-1.

35. Mattos MA, Sumner DS, Bohannon WT, Parra J, McLafferty RB, Karch LA, et al. Carotid endarterectomy in women: challenging the results from ACAS and NASCET. Ann Surg. 2001;234(4):438-45. discussion 45-6.

36. James DC, Hughes JD, Mills $J$, Westerband A. The influence of gender on complications of carotid endarterectomy. Am J Surg. 2001;182(6):654-7.

37. Sarac TP, Hertzer NR, Mascha EJ, O'Hara PJ, Krajewski LP, Clair DG, et al. Gender as a primary predictor of outcome after carotid endarterectomy. J Vasc Surg. 2002;35(4):748-53.

38. Kapral MK, Wang H, Austin PC, Fang J, Kucey D, Bowyer B, et al. Sex differences in carotid endarterectomy outcomes: results from the Ontario Carotid Endarterectomy Registry. Stroke. 2003;34(5):1120-5. doi:10.1161/ 01.STR.0000066681.79339.E2 01.STR.0000066681.79339.E2.

39. Lane JS, Shekherdimian S, Moore WS. Does female gender or hormone replacement therapy affect early or late outcome after carotid endarterectomy? J Vasc Surg. 2003;37(3):568-74. doi:10.1067/mva.2003.96

40. Friedmann P, Garb JL, Berman J, Sullivan C, Celoria G, Rhee SW. Carotid endarterectomy. Clinical results in a community-based teaching hospital. Stroke. 1988;19(11):1323-7.

41. Riles TS, Imparato AM, Jacobowitz GR, Lamparello PJ, Giangola G, Adelman MA, et al. The cause of perioperative stroke after carotid endarterectomy. J Vasc Surg. 1994;19(2):206-14. discussion 15-6.

42. Maxwell JG, Rutherford EJ, Covington DL, Churchill P, Patrick RD, Scott C, et al. Community hospital carotid endarterectomy in patients over age 75 . Am J Surg. 1990;160(6):598-603.

43. Magnan PE, Caus T, Branchereau A, Rosset E, Prima F. Internal carotid artery surgery: ten-year results. Ann Vasc Surg. 1993;7(6):521-9.

44. Goldstein LB, McCrory DC, Landsman PB, Samsa GP, Ancukiewicz M, Oddone EZ, et al. Multicenter review of preoperative risk factors for carotid endarterectomy in patients with ipsilateral symptoms. Stroke. 1994;25(6):1116-21.

45. Plestis KA, Kantis G, Haygood K, Earl N, Howell JF. Carotid endarterectomy with homologous vein patch angioplasty: a review of 1006 cases. J Vasc Surg. 1996;24(1):109-19.

46. Hertzer NR, O'Hara PJ, Mascha EJ, Krajewski LP, Sullivan TM, Beven EG. Early outcome assessment for 2228 consecutive carotid endarterectomy procedures: the Cleveland Clinic experience from 1989 to 1995. J Vasc Surg. 1997;26(1):1-10.

47. Kerdiles Y, Lucas A, Podeur L, Ferte P, Cardon A. Results of carotid surgery in elderly patients. J Cardiovasc Surg (Torino). 1997;38(4):327-34

48. Kucey DS, Bowyer B, Iron K, Austin P, Anderson G, Tu JV. Determinants of outcome after carotid endarterectomy. J Vasc Surg. 1998;28(6):1051-8.

49. Karp HR, Flanders WD, Shipp CC, Taylor B, Martin D. Carotid endarterectomy among Medicare beneficiaries: a statewide evaluation of appropriateness and outcome. Stroke. 1998;29(1):46-52.

50. Blohme L, Sandstrom V, Hellstrom G, Swedenborg J, Takolander R Complications in carotid endarterectomy are predicted by qualifying symptoms and preoperative CT findings. Eur J Vasc Endovasc Surg. 1999;17(3):213-8.

51. Hartmann A, Hupp T, Koch HC, Dollinger P, Stapf C, Schmidt R, et al. Prospective study on the complication rate of carotid surgery. Cerebrovasc Dis. 1999;9(3):152-6

52. Ackerstaff RG, Moons KG, van de Vlasakker CJ, Moll FL, Vermeulen FE, Algra A, et al. Association of intraoperative transcranial doppler monitoring variables with stroke from carotid endarterectomy. Stroke. 2000;31(8):1817-23.

53. Frawley JE, Hicks RG, Woodforth IJ. Risk factors for peri-operative stroke complicating carotid endarterectomy: selective analysis of a prospective audit of 1000 consecutive operations. Aust N Z J Surg. 2000;70(1):52-6.

54. Naylor AR, Hayes PD, Allroggen H, Lennard N, Gaunt ME, Thompson MM, et al. Reducing the risk of carotid surgery: a 7-year audit of the role of monitoring and quality control assessment. J Vasc Surg. 2000;32(4):750-9.

55. Eckstein HH, Ringleb P, Dorfler A, Klemm K, Muller BT, Zegelman M, et al. The Carotid Surgery for Ischemic Stroke trial: a prospective observational study on carotid endarterectomy in the early period after ischemic stroke. J Vasc Surg. 2002;36(5):997-1004.

56. Barnett HJ, Taylor DW, Eliasziw M, Fox AJ, Ferguson GG, Haynes RB, et al. Benefit of carotid endarterectomy in patients with symptomatic moderate or severe stenosis. North American Symptomatic Carotid Endarterectomy
Trial Collaborators. N Engl J Med. 1998;339(20):1415-25 doi:10.1056/NEJM199811123392002

57. Taylor DW, Barnett HJ, Haynes RB, Ferguson GG, Sackett DL, Thorpe KE, et al Low-dose and high-dose acetylsalicylic acid for patients undergoing carotid endarterectomy: a randomised controlled trial. ASA and Carotid Endarterectomy (ACE) Trial Collaborators. Lancet. 1999;353(9171):2179-84.

58. Luebke T, Aleksic M, Brunkwall J. Meta-analysis of randomized trials comparing carotid endarterectomy and endovascular treatment. Eur J Vasc Endovasc Surg. 2007;34(4):470-9

59. Guzman RP, Weighell W, Guzman C, Rodriguez-Leyva D. Female Sex Does Not Influence 30-Day Stroke and Mortality Rates After Carotid Endarterectomy. Ann Vasc Surg. 2013.

60. Timaran CH, Mantese VA, Malas M, Brown OW, Lal BK, Moore WS, et al. Differential outcomes of carotid stenting and endarterectomy performed exclusively by vascular surgeons in the Carotid Revascularization Endarterectomy versus Stenting Trial (CREST). J Vasc Surg. 2013;57(2):303-8.

61. Baracchini C, Saladini M, Lorenzetti R, Manara R, Da Giau G, Ballotta E. Gender-based outcomes after eversion carotid endarterectomy from 1998 to 2009. J Vasc Surg. 2012;55(2):338-45.

62. Bisdas T, Egorova N, Moskowitz AJ, Sosunov EA, Marin ML, Faries PL, et al. The impact of gender on in-hospital outcomes after carotid endarterectomy or stenting. Eur J Vasc Endovasc Surg. 2012;44(3):244-50.

63. Menyhei G, Bjorck M, Beiles B, Halbakken E, Jensen LP, Lees T, et al. Outcome following carotid endarterectomy: lessons learned from a large international vascular registry. Eur J Vasc Endovasc Surg. 2011;41(6):735-40.

64. Rockman CB, Garg K, Jacobowitz GR, Berger JS, Mussa FF, Cayne NS, et al. Outcome of carotid artery interventions among female patients, 2004 to 2005. J Vasc Surg. 2011;53(6):1457-64.

65. Poisson SN, Johnston SC, Sidney S, Klingman JG, Nguyen-Huynh MN Gender differences in treatment of severe carotid stenosis after transient ischemic attack. Stroke. 2010;41(9):1891-5.

66. Yavas S, Mavioglu L, Kocabeyoglu S, Iscan HZ, Ulus AT, Bayazit M, et al. Is female gender really a risk factor for carotid endarterectomy? Ann Vasc Surg. 2010;24(6):775-85.

67. Fiehler J, Bakke SJ, Clifton A, Houdart E, Jansen O, Rufenacht D, et al. Plea of the defence-critical comments on the interpretation of EVA3S, SPACE and ICSS. Neuroradiology. 2010;52(7):601-10. doi:10.1007/s00234-010-0707-4.

68. Mas JL, Chatellier G, Beyssen B, Branchereau A, Moulin T, Becquemin JP, et al. Endarterectomy versus stenting in patients with symptomatic severe carotid stenosis. N Engl J Med. 2006;355(16):1660-71.

69. Eckstein HH, Ringleb P, Allenberg JR, Berger J, Fraedrich G, Hacke W, et al. Results of the Stent-Protected Angioplasty versus Carotid Endarterectomy (SPACE) study to treat symptomatic stenoses at 2 years: a multinational, prospective, randomised trial. Lancet Neurol. 2008;7(10):893-902.

70. Featherstone RL, Brown MM, Coward LJ. International carotid stenting study: protocol for a randomised clinical trial comparing carotid stenting with endarterectomy in symptomatic carotid artery stenosis. Cerebrovasc Dis. 2004;18(1):69-74. doi:10.1159/000078753.

71. Dorigo W, Pulli R, Marek J, Troisi N, Pratesi G, Innocenti AA, et al. Carotid endarterectomy in female patients. J Vasc Surg. 2009;50(6):1301-6. discussion 6-7.

72. Sidawy AN, Zwolak RM, White RA, Siami FS, Schermerhorn ML, Sicard GA. Risk-adjusted 30-day outcomes of carotid stenting and endarterectomy: results from the SVS Vascular Registry. J Vasc Surg. 2009;49(1):71-9.

73. Halm EA, Tuhrim S, Wang JJ, Rockman C, Riles TS, Chassin MR. Risk factors for perioperative death and stroke after carotid endarterectomy: results of the new york carotid artery surgery study. Stroke. 2009;40(1):221-9.

74. Ederle J, Featherstone RL, Brown MM. Long-term outcome of endovascular treatment versus medical care for carotid artery stenosis in patients not suitable for surgery and randomised in the Carotid and Vertebral Artery Transluminal Angioplasty study (CAVATAS). Cerebrovasc Dis. 2009;28(1):1-7.

75. Park B, Aiello F, Dahn MS, Menzoian JO, Mavanur A. No gender influences on clinical outcomes or durability of repair following carotid angioplasty with stenting and carotid endarterectomy. Vasc Endovascular Surg. 2008;42(4):321-8.

76. Dalainas I, Nano G, Bianchi P, Casana R, Malacrida G, Tealdi DG. Carotid endarterectomy in patients with contralateral carotid artery occlusion. Ann Vasc Surg. 2007;21(1):16-22.

77. Hugl B, Oldenburg WA, Neuhauser B, Hakaim AG. Effect of age and gender on restenosis after carotid endarterectomy. Ann Vasc Surg. 2006;20(5):602-8. doi:10.1007/s10016-006-9028-9. 
78. Harthun NL, Kongable GL, Baglioni AJ, Meakem TD, Kron IL. Examination of sex as an independent risk factor for adverse events after carotid endarterectomy. J Vasc Surg. 2005;41(2):223-30.

79. Tu JV, Wang H, Bowyer B, Green L, Fang J, Kucey D. Risk factors for death or stroke after carotid endarterectomy: observations from the Ontario Carotid Endarterectomy Registry. Stroke. 2003;34(11):2568-73. doi:10.1161/ 01.STR.0000092491.45227.0F.

80. Goldstein LB, Samsa GP, Matchar DB, Oddone EZ. Multicenter review of preoperative risk factors for endarterectomy for asymptomatic carotid artery stenosis. Stroke. 1998:29(4):750-3.

81. Huber TS, Wheeler KG, Cuddeback JK, Dame DA, Flynn TC, Seeger JM. Effect of the Asymptomatic Carotid Atherosclerosis Study on carotid endarterectomy in Florida. Stroke. 1998;29(6):1099-105.

82. McCrory DC, Goldstein LB, Samsa GP, Oddone EZ, Landsman PB, Moore WS, et al. Predicting complications of carotid endarterectomy. Stroke. 1993;24(9):1285-91.

83. Lee JW, Pomposelli F, Park KW. Association of sex with perioperative mortality and morbidity after carotid endarterectomy for asymptomatic carotid stenosis. J Cardiothorac Vasc Anesth. 2003;17(1):10-6. doi:10.1053/jcan.2003.3.

84. Weise J, Kuschke S, Bahr M. Gender-specific risk of perioperative complications in carotid endarterectomy patients with contralateral carotid artery stenosis or occlusion. J Neurol. 2004:251(7):838-44. doi:10.1007/s00415-004-0438-8.

85. Harthun NL, Baglioni Jr AJ, Kongable GL, Meakem TD, Cherry KJ. Carotid endarterectomy: update on the gold standard treatment for carotid stenosis. Am Surg. 2005;71(8):647-51. discussion 51-2.

86. Ramani S, Byrne-Logan S, Freund KM, Ash A, Yu W, Moskowitz MA. Gender differences in the treatment of cerebrovascular disease. J Am Geriatr Soc. 2000:48(7):741-5.

87. Hill MD, Brooks W, Mackey A, Clark WM, Meschia JF, Morrish WF, et al. Stroke after carotid stenting and endarterectomy in the Carotid Revascularization Endarterectomy versus Stenting Trial (CREST). Circulation. 2012;126(25):3054-61.

88. Howard VJ, Lutsep HL, Mackey A, Demaerschalk BM, Sam 2nd AD, Gonzales $N R$, et al. Influence of sex on outcomes of stenting versus endarterectomy: a subgroup analysis of the Carotid Revascularization Endarterectomy versus Stenting Trial (CREST). Lancet Neurol. 2011;10(6):530-7.

89. Brott TG, Halperin JL, Abbara S, Bacharach JM, Barr JD, Bush RL, et al. ASA/ACCF/ AHAVAANN/AANS/ACR/ASNR/CNS/SAIP/SCAI/SIR/SNIS/SVM/SVS guideline on the management of patients with extracranial carotid and vertebral artery disease: executive summary. J Neurointerv Surg. 2011;3(2):100-30.

90. Brott TG, Halperin JL, Abbara S, Bacharach JM, Barr JD, Bush RL, et al. ASA ACCF/AHA/AANN/AANS/ACR/ASNR/CNS/SAIP/SCAI/SIR/SNIS/SVM/SVS guideline on the management of patients with extracranial carotid and vertebral artery disease: a report of the American College of Cardiology Foundation/American Heart Association Task Force on Practice Guidelines, and the American Stroke Association, American Association of Neuroscience Nurses, American Association of Neurological Surgeons, American College of Radiology, American Society of Neuroradiology, Congress of Neurological Surgeons, Society of Atherosclerosis Imaging and Prevention, Society for Cardiovascular Angiography and Interventions, Society of Interventional Radiology, Society of Neurolnterventional Surgery, Society for Vascular Medicine, and Society for Vascular Surgery. J Am Coll Cardiol. 2011;57(8):e16-94.

91. Ederle J, Dobson J, Featherstone RL, Bonati LH, van der Worp HB, de Borst GJ, et al. Carotid artery stenting compared with endarterectomy in patients with symptomatic carotid stenosis (International Carotid Stenting Study): an interim analysis of a randomised controlled trial. Lancet. 2010;375(9719):985-97.

92. Feinglass J, McDermott MM, Foroohar M, Pearce WH. Gender differences in interventional management of peripheral vascular disease: evidence from a blood flow laboratory population. Ann Vasc Surg. 1994;8(4):343-9.

93. Sonis J, Doukas D, Klinkman M, Reed B, Ruffin MTT. Applicability of clinical trial results to primary care. JAMA. 1998;280(20):1746.

94. Fahey T. Applying the results of clinical trials to patients to general practice: perceived problems, strengths, assumptions, and challenges for the future. Br J Gen Pract. 1998;48(429):1173-8.

95. Bond R, Rerkasem K, Cuffe R, Rothwell PM. A systematic review of the associations between age and sex and the operative risks of carotid endarterectomy. Cerebrovasc Dis. 2005;20(2):69-77.
96. den Hartog AG, Algra A, Moll FL, de Borst GJ. Mechanisms of gender-related outcome differences after carotid endarterectomy. J Vasc Surg. 2010;52(4):1062-71.

97. Comerota AJ, Salles-Cunha SX, Daoud Y, Jones L, Beebe HG. Gender differences in blood velocities across carotid stenoses. J Vasc Surg. 2004:40(5):939-44.

98. Hellings WE, Pasterkamp G, Verhoeven BA, De Kleijn DP, De Vries JP, Seldenrijk KA, et al. Gender-associated differences in plaque phenotype of patients undergoing carotid endarterectomy. J Vasc Surg. 2007:45(2):289-96. discussion 96-7.

99. Rothwell PM, Slattery J, Warlow CP. Clinical and angiographic predictors of stroke and death from carotid endarterectomy: systematic review. BMJ. 1997;315(7122):1571-7.

100. Lal BK, Brott TG. Restenosis after carotid endarterectomy and stenting-authors' reply. Lancet Neurol. 2013;12(2):130-1.

101. Rerkasem K, Rothwell PM. Patches of different types for carotid patch angioplasty. Cochrane Database Syst Rev. 2010;3, CD000071.

102. Stork JL, Levi CR, Chambers BR, Abbott AL, Donnan GA. Possible determinants of early microembolism after carotid endarterectomy. Stroke. 2002;33(8):2082-5.

103. Laman DM, Wieneke GH, van Duijn H, van Huffelen AC. High embolic rate early after carotid endarterectomy is associated with early cerebrovascular complications, especially in women. J Vasc Surg. 2002;36(2):278-84.

104. Giannopoulos S, Katsanos AH, Vasdekis SN, Boviatsis E, Voumvourakis Kl, Tsivgoulis G. Age and gender disparities in the risk of carotid revascularization procedures. Neurol Sci. 2013.

105. Ederle J, Featherstone RL, Brown MM. Randomized controlled trials comparing endarterectomy and endovascular treatment for carotid artery stenosis: a Cochrane systematic review. Stroke. 2009;40(4):1373-80.

\section{Submit your next manuscript to BioMed Central and take full advantage of:}

- Convenient online submission

- Thorough peer review

- No space constraints or color figure charges

- Immediate publication on acceptance

- Inclusion in PubMed, CAS, Scopus and Google Scholar

- Research which is freely available for redistribution 